\title{
On Zyras sensu strictu in the East Palaearctic and Oriental regions III, with a focus on the Southeast of Continental Asia and the Sunda Islands (Coleoptera: Staphylinidae: Aleocharinae: Lomechusini)
}

With 102 figures, 1 key and 1 table

VOLKER ASSING ${ }^{1}$

${ }^{1}$ Gabelsbergerstraße 2, 30163 Hannover, Germany. - vassing.hann@t-online.de

Published on 2017-12-08

DOI: $110.21248 /$ contrib.entomol.67.2.213-246

\section{Abstract}

Species of the nominal subgenus of the lomechusine genus Zyras STEPHENS, 1835 of the southeastern Oriental region are revised. Eighteen species are (re-)described and/or illustrated, six of them for the first time: Zyras (Zyras) latibasalis spec. nov. (Java, tentatively recorded also from Laos), Z. (Z.) rutrilobatus spec. nov. (Laos), Z. (Z.) parvilobatus spec. nov. (Laos), Z. (Z.) hirtiventris spec. nov. (Laos, Vietnam), Z. (Z.) hlavaci spec. nov. (Malaysia: Pahang, Selangor), Z. (Z.) lunatus spec. nov. (Malaysia: Selangor). Eight synonymies are proposed: Zyras bryanti CAMERon, 1943 =Z. mortuorum PACE, 1990, syn. nov., =Z. paederinus PACE, 2008, syn. nov.; Zyras nigerrimus CAmeron, $1943=$ Z. bartolozzii PACE, 2003, syn. nov., = Z. alboterminalis PACE, 2008, syn. nov.; Z. granulipennis Cameron, $1930=$ Z. pervariolosus PaCe, 2008, syn. nov.; Z. matangensis CAmeron, $1943=$ Z. daiaccorum PaCE, 2008, syn. nov.; Z. montanus (Bernhauer, 1915) = Z. variolatus PaCe, 2003, syn. nov.; Z. preangeranus CAmeron, 1939 = Z. quadriterminalis PACE, 2008, syn. nov. One species is excluded from Zyras: Myrmedonota modiglianii (CAmeron, 1925), comb. nov. Lectotypes are designated for Zyras elegantulus Cameron, 1939, Z. semirufus CAMERon, 1939, and $Z$. flavus CAMERON, 1939. Additional records of nine named species are reported. A key to the species recorded from the southeastern Oriental region and an updated catalogue of the species of the Palaearctic and Oriental regions are provided. The subgenus is currently represented in the Palaearctic and Oriental regions by a total of 122 described species. Twenty-two species have been recorded from Sunda Islands. The countries with the greatest diversity are China (46 named species), India (20), Indonesia (19), Malaysia (15), Thailand (14), Nepal (12), Laos (11), and Vietnam (8).

\section{Nomenclatural acts}

Zyras (Zyras) latibasalis spec. nov. -urn:lsid:zoobank.org:act:35276B1A-6492-4F55-8836-91058719625G

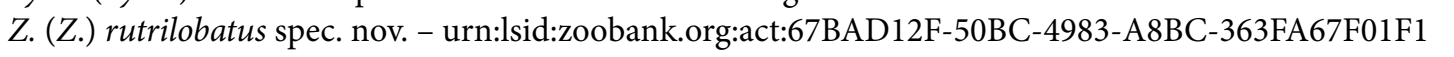

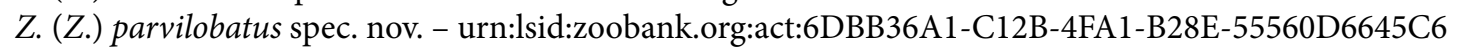

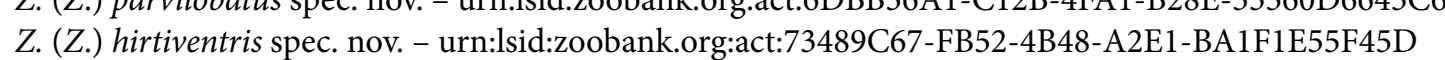

Z. (Z.) hlavaci spec. nov. - urn:lsid:zoobank.orgact F5734436-CE49-4064-8A52-BC7DF9A0EE671

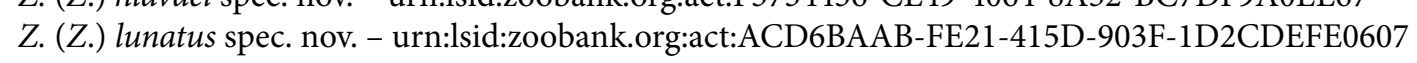




\section{Key words}

Coleoptera, Staphylinidae, Aleocharinae, Lomechusini, Oriental region, taxonomy, new species, new synonymies, new combination, lectotype designations, key to species, catalogue, additional records.

\section{Zusammenfassung}

Arten der Untergattung Zyras Stephens, 1835 der südöstlichen Orientalis werden revidiert. Achtzehn Arten werden beschrieben und/oder abgebildet, davon sechs neu: Zyras (Zyras) latibasalis spec. nov. (Java, wahrscheinlich auch Laos), Z. (Z.) rutrilobatus spec. nov. (Laos), Z. (Z.) parvilobatus spec. nov. (Laos), Z. (Z.) hirtiventris spec. nov. (Laos, Vietnam), Z. (Z.) hlavaci spec. nov. (Malaysia: Pahang, Selangor), Z. (Z.) lunatus spec. nov. (Malaysia: Selangor). Acht Namen werden synonymisiert: Zyras bryanti CAMERon, $1943=$ Z. mortuorum PACE, 1990, syn. nov., =Z. paederinus PACE, 2008, syn. nov.; Zyras nigerrimus CAMERon, 1943 = Z. bartolozzii PACE, 2003, syn. nov., = Z. alboterminalis PACE, 2008, syn. nov.; Z. granulipennis CAMERon, 1930 = Z. pervariolosus PACE, 2008, syn. nov.; Z. matangensis CAMERon, 1943 = Z. daiaccorum PACE, 2008, syn. nov.; Z. montanus (Bernhauer, 1915) = Z. variolatus PaCe, 2003, syn. nov.; Z. preangeranus CAMERon, $1939=$ Z. quadriterminalis PACE, 2008, syn. nov. Eine Art wird aus der Gattung Zyras enfernt: Myrmedonota modiglianii (CAMERon, 1925), comb. nov. Für Zyras elegantulus CAMERon, 1939, Z. semirufus Cameron, 1939 und Z. flavus Cameron, 1939 werden Lektotypen designiert. Weitere Nachweise von neun Arten werden gemeldet. Eine Bestimmungstabelle der Arten der südöstlichen Orientalis und ein aktualisierter Katalog der beschriebenen Arten der Paläarktis und der Orientalis werden erstellt. Zyras sensu strictu ist in der Paläarktis und der Orientalis derzeit mit insbesamt 122 beschriebenen Arten vertreten, von denen 22 auf den Sunda-Inseln nachgewiesen wurden. Die Länder mit der höchsten Diversität sind China (46 beschriebene Arten), Indien (20), Indonesia (19), Malaysia (15), Thailand (14), Nepal (12), Laos (11) und Vietnam (8).

\section{Introduction}

According to recent revisions (Assing 2016a, 2017), the nominal subgenus of Zyras STEPHENs, 1833 was represented in the Palaearctic and Oriental regions sensu Schülke \& Smetana (2015) by 124 named and several unnamed species. However, a significant number of species, particularly species described from the Sunda Islands, had not been revised. In view of the considerable number of previously discovered new species and new synonymies, significant taxonomic changes were to be expected.

The present study focuses on previously unrevised species described from Peninsular Malaysia, Java, Sumatra, Borneo, and the Philippines, as well as additional material from southeastern Continental Asia and the Sunda Islands. A revision of this material yielded six new species, eight new synonymies (one of them only changing synonymic status), and a new combination.

In the course of the present study it was discovered that the illustrations of the aedeagus of Z. maculicollis Assing, 2016 and Z. notaticornis PACE, 1998 in Assing (2016a) are confused: figures 221-222 refer to $Z$. notaticornis and figures $225-226$ to $Z$. maculicollis.

\section{Material and methods}

The material treated in this study is deposited in the following collections:
BMNH The Natural History Museum, London (M. Barclay, R. Booth)

MHNG Muséum d'Histoire Naturelle, Genève (G. Cuccodoro)

MNHNP Muséum National d'Histoire Naturelle, Paris (A. Taghavian)

MZMB Moravské Zemské Muzeum Brno (via M. Schülke)

MZUF Museo di Zoologia, Università di Firenze (L. Bartolozzi)

NMP National Museum of Natural History, Praha (J. Hájek)

cAss author's private collection

cHla private collection Peter Hlaváč, Prague

cMar private collection Munetoshi Maruyama, Fukuoka

The morphological studies were conducted using a Stemi SV 11 microscope (Zeiss Germany) and a Jenalab compound microscope (Carl Zeiss Jena). The images were created using a photographing device constructed by Arved Lompe (Nienburg) and CombineZ software, as well as a digital camera (Nikon Coolpix 995).

Body length was measured from the anterior margin of the labrum to the abdominal apex, the length of the forebody from the anterior margin of the labrum to the posterior margin of the elytra, head length from the anterior margin of the clypeus (without ante-clypeus) to the posterior constriction of the head, elytral length at the suture from the apex of the scutellum to the posterior 
margin of the elytra, and the length of the aedeagus from the apex of the ventral process to the base of the aedeagal capsule. The "parameral" side (i.e., the side where the sperm duct enters) is referred to as the ventral, the opposite side as the dorsal aspect.

\section{Results}

\subsection{General remarks}

The present study yielded six species new to science, three from Laos (one of them recorded also from Vietnam), two from Peninsular Malaysia, and one from Java (tentatively recorded also from Laos). Moreover, based on a revision of type material, one species previously assigned to Zyras sensu strictu is moved to Myrmedonota CAmeron, 1920. Finally, eight new synonymies were discoved, most of them affecting species distributed in the Sunda Islands and in Peninsular Malaysia.

Thus, with practically all the species revised, except for those from Japan and the West Palaearctic (including Middle Asia), the Zyras sensu strictu fauna is currently composed of 122 described species. However, in the course of the present and previous revisions, numerous additional unnamed species were seen, which were represented exclusively by females and/or teneral males and which were consequently not described. Also, most of the East Palaearctic and Oriental regions has not been sampled thoroughly. Further, a significant proportion of the revised material has been collected exclusively with light, flight interception, and Malaise traps, methods that are known to be suitable only for a minority of species. Finally, numerous species are represented only by single or very few specimens. In consequence, it can be concluded that the true diversity of Zyras sensu strictu in these regions is significantly greater than currently known and numerous additional species remain to be discovered and described. At present, the regions with the greatest diversity of Zyras sensu strictu are China (46 named species), India (20), Indonesia (19), Malaysia (15), Thailand (14), Nepal (12), Laos (11), and Vietnam (8).

In all, 22 species have been recorded from the Sunda Islands. Nine of these species - including Z. latibasalis, whose record from Laos is only tentative - are known also from the South Asian mainland. The remainder has been recorded only from Borneo (five species), Sulawesi (four), Java (three), and Bali (one).

Interpretation and identification of Zyras sensu strictu species are often difficult, mainly as a result of sometimes remarkable intraspecific variation (particularly so in widespread species) combined with generally little interspecific variation. This partly explains the considerable number of now invalid names. Prior to the present revision (Assing 2016a, 2017, and this paper), the authors that described most of the Zyras sensu strictu species were Cameron (24 names) and Pace (41 names), wrongly assigned species (i.e., species now in other genera or subgenera) not included. Of the names authored by Cameron, 17 are still valid, five are synonyms and two homonyms. Even more remarkable are the figures for Pace names: only 13 (32\%) of them are still valid, 27 are synonyms and one is a junior homonym.

\subsection{Key to the species of the subgenus Zyras of the Oriental Region (sensu SchüLKE \& SMETANA 2015), exclusive of India, Sri Lanka, and Myanmar}

In all, 45 species are currently known from the southeastern Oriental regions (comprising Thailand, Laos, Vietnam, Peninsular Malaysia, and the Sunda Islands).

A positive identification of females without reference material may not always be possible. The same applies to aberrant (e.g., regarding coloration) or nanistic specimens. Two variable species, Z. gratellus and Z. punctipennis, key out in more than one couplet.

1. Punctation of pronotum and elytra conspicuously coarse and dense (e.g., Fig. 30).

- Punctation of pronotum and elytra not conspicuously coarse and dense (though sometimes very fine and dense, or only the elytra with coarse and dense punctation).

2. Punctation of pronotum and elytra strongly and conspicuously coarsely granulose (Fig. 30). Body smaller and more slender, of predominantly brown coloration. Antennae reddish (Fig. 7). Pronotum nearly as long as broad, strongly convex in cross-section, and with sinuate lateral margins in dorsal view (Fig. 30). Median lobe of aedeagus as in Figs 66-67. Borneo. granulipennis

- Punctation of pronotum and elytra not distinctly granulose. Body larger and more robust, of predominantly black coloration. Antennae bicoloured, dark-brown to blackish-brown with the apical 1-2 antennomeres yellow. Pronotum distinctly transverse, moderately convex in cross-section; lateral margins not sinuate in dorsal view. Median lobe of aedeagus as in Assing (2017: figures 266-267, 271-272). Borneo, Peninsular Malaysia. montanus

3. Forebody with conspicuously dense and fine punctation. Small species; length of forebody 1.7-2.1 mm. Antennae slender, preapical antennomeres not transverse. 
- Punctation of forebody not conspicuously dense and fine. Mostly larger species. Preapical antennomeres mostly transverse.

4. Punctation of forebody finer and denser (Assing 2017: figure 75). Pronotum dark-brown, of similar coloration as head (Assing 2017: figure 75). Median lobe of aedeagus as in Assing (2017: figures 239-241). Sulawesi.

densissimus

- Punctation of forebody less fine and less dense (Fig. 23). Pronotum pale-reddish, distinctly contrasting with the dark-brown to blackish head. Median lobe of aedeagus as in Figs 59-60. Widespread in the Oriental region.

bryanti

5. Antennae short ( $<1.5 \mathrm{~mm}$ long) and clavate; antennomeres IV-X transverse, $\mathrm{X}$ at least approximately twice as broad as long. Body rather small (length of forebody $2.4-2.5 \mathrm{~mm}$ ) and of predominantly reddish coloration, with the head reddish to reddish-brown and the pronotum pale reddish. Forebody moderately sparsely or very sparsely punctate.

- Character combination different. Antennae usually longer and more slender, with antennomere IV weakly transverse at most. Species of similarly small size have at least the head darker.

6. Antennomere IV disc-shaped, approximately twice as broad as long (Fig. 17). Elytra with very sparse punctation; interstices on average more than twice as broad as diameter of punctures (Fig. 22). Pronotum small in relation to head, approximately 1.2 times as broad as head (Fig. 22). Male sexual characters unknown. Borneo. ...... pallipyga

- Antennomere IV noticeably transverse, but not disc-shaped (Fig. 16). Elytra with moderately dense punctation; interstices on average twice as broad as diameter of punctures at most (Fig. 20). Pronotum large in relation to head, $>1.35$ times as broad as head (Fig. 20). Median lobe of aedeagus as in Figs 53-54. Java. elegantulus

7. Pronotum reddish or pale-reddish, strongly constrasting with the blackish head and elytra. Abdomen distinctly bicoloured, with segments III-V or III-VI reddish and the posterior segments at least partly blackish. ............. 8

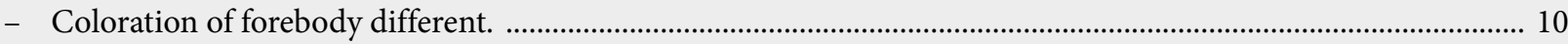

8. Antennomere XI dark-brown to black (Assing 2017: figure 20). Legs of uniformly yellowish coloration. Pronotum strongly transverse, 1.15-1.18 times as broad as long. Elytra with coarser and sparser punctation (Assing 2017: figure 58). Median lobe of aedeagus as in Assing (2017: 166-167). Widespread (Assing 2017: map 8).

alternans

- Apical 1-3 antennomeres yellow, much paler than antennomeres IV-VII. Legs with at least the apices of the mesoand metafemora slightly to distinctly infuscate. Elytra with denser and finer punctation. Median lobe of aedeagus of different shape.

9

9. Profemora and the apical halves of the meso- and metafemora blackish. Antennomere X blackish. Pronotum dark-reddish. Elytra with distinct punctation. Median lobe of aedeagus as in PACE (1986a: figures 120-121). Thailand.

thaiorum

- Apices of femora only slightly and narrowly infuscate; profemora often uniformly yellowish. Antennomere X and often also antennomere IX yellowish. Pronotum pale-reddish. Elytra with very fine punctation. Median lobe of aedeagus as in Assing (2016a: figures 274-281). Widespread (Assing 2017: map 8). geminus

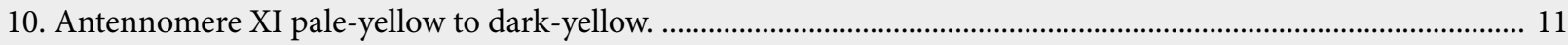

- Antennomere XI reddish to black. (In cases of doubt regarding this character follow both alternatives.). ......... 26

11. Small (length of forebody approximately $2.4 \mathrm{~mm}$ ) and micropterous species with short elytra and reduced hind wings; elytra $0.65-0.75$ times as long as pronotum. ................................................................................................ 12

- Macropterous species with longer elytra and long hind wings. Body usually larger. ........................................... 13

12. Antennae uniformly dark-yellowish (Fig. 4). Pronotum and elytra with coarse and dense punctation (Fig. 21). Antennomere XI shorter than the combined length of antennomeres IX and X; antennomere X weakly transverse (Fig. 4). Anterior abdominal tergites dark-brown (Fig. 44). Mesofemora uniformly yellowish. Median lobe of aedeagus as in PACE (2008: figures 98-99). Borneo.

kinabaluensis

- Antennomeres IV-X dark-brown (Assing 2017: figure 34). Pronotum and elytra with sparser and finer punctation (Assing 2017: figure 70). Antennomere XI approximately as long as the combined length of antennomeres IX and $\mathrm{X}$; antennomere X distinctly transverse (Assing 2017: figure 34). Meso- and metafemora apically infuscate. Median lobe of aedeagus as in Assing (2017: figures 212-213). Thailand. ambulans 
13. Legs bicoloured, yellowish with at least the metafemora distinctly infuscate apically. Pronotum brown to black.

- Legs uniformly yellowish, apices of meso- and metafemora in one variable large species with reddish pronotum sometimes indistinctly darker.

14. Meso- and metafemora apically narrowly infuscate. Elytra with very dense punctation. Antennae not particularly long and slender; antennomere IV indistinctly oblong at most.

- Meso- and metafemora apically extensively infuscate. Elytra with moderately dense punctation. Antennae long and slender; antennomere IV at least approximately twice as long as broad (species of the Z. nitens group).

15. Body black. Antennomeres IX-XI pale-yellow. Elytra with distinctly finer punctation (Assing 2017: figure 77). Anterior impressions of tergites III and IV with very fine and scattered non-setiferous punctation (AssiNG 2017: figure 115). Median lobe of aedeagus as in Assing (2017: figures 250-251). Sulawesi. densihirtus

- Head and pronotum brown (Fig. 19); elytra bicoloured, reddish with the postero-lateral portions infuscate Fig. 19); abdomen partly reddish to reddish-brown (Fig. 34). Elytra with coarse punctation (Fig. 19). Anterior impressions of tergites III and IV with coarse and dense non-setiferous punctation (Fig. 34). Male sexual characters unknown. Java. punctipennis

16. Pronotum more strongly transverse, approximately 1.2 times as broad as long (Fig. 31). Pronotum and elytra with sparser and finer punctation (Fig. 31). Median lobe of aedeagus as in Figs 81-82. Laos. rutrilobatus

- Pronotum more slender, approximately 1.1 times as long. Pronotum and elytra with denser and coarser punctation.

17. Species of slightly smaller body size and with weakly infuscate apical halves of the meso- and metafemora. Male sternite VIII apically acute and somewhat bifid (Assing 2017: figure 221). Median lobe of aedeagus as in AssING (2017: figures 216-217). Peninsular Malaysia. nitens

- Slightly larger species with the apical halves of the meso- and metafemora blackish. Male sternite VIII and median lobe of aedeagus of different shapes. (Male sexual characters of Z. brignolii are unknown.). 18

18. Antennae more slender; antennomeres IX-X distinctly oblong. Antennomere XI pale-yellowish. Male sternite VIII obtusely pointed posteriorly. Ventral process of aedeagus (PACE 2003: figures 87-88) conspicuously broad in ventral view. Peninsular Malaysia; Borneo. nigerrimus

- Antennae less slender; antennomeres IX-X weakly transverse (Assing 2017: figure 15). Antennomere XI darkyellowish. Male sexual characters unknown. Thailand; China: Yunnan. brignolii

19. Pronotum reddish. Large to very large species (species of the Z. hirtus group). 20

- Pronotum dark-brown to blackish. Species of relatively small to large size.

20. Head pale-reddish, of similar coloration as pronotum; elytra dark-brown to blackish with the anterior margin reddish (AssING 2017: figure 61); abdomen distinctly bicoloured, with tergites III-V reddish and VI-VIII extensively blackish (Assing 2017: figure 114). Median lobe of aedeagus as in Assing (2017: figures 187-188). Thailand; Peninsular Malaysia. russiceps

- Head reddish-brown to black, darker than the pronotum; elytra uniformly reddish, or reddish with the posterolateral portions more or less distinctly infuscate; abdomen not distinctly bicoloured. Larger species. 21

21. Largest species of the subgenus in the Oriental region; length of forebody 4.0-4.3 mm. Pronotum slender, less than 1.1 times as broad as long (Assing 2017: figure 76). Elytra with coarse punctation (Assing 2017: figure 76). Anterior impressions of tergites III-V with coarse and dense non-setiferous punctation (Assing 2017: figure 113). Median lobe of aedeagus as in Assing (2017: figures 245-246). Sulawesi. titan

- Large species, but less so than Z. titan; length of forebody less than $4.0 \mathrm{~mm}$. Pronotum more transverse, approximately 1.15 times as broad as long. Elytra with fine and dense punctation. Anterior impressions of tergites III-V with fine and sparse non-setiferous punctation. Median lobe of aedeagus as in Assing (2017: 276-277). Widespread (Assing 2017: map 10). preangeranus

22. Elytra with conspicuously coarse and dense punctation (Fig. 19). Pronotum strongly convex in cross-section and weakly transverse, approximately 1.1 times as broad as long (Fig. 19). Head and pronotum dark-brown to blackishbrown; elytra dark-reddish with infuscate postero-lateral portions (Fig. 19). Large species; body length 6.5-8.0 mm; length of forebody 3.0-3.5 mm. Male sexual characters unknown. Java, Borneo. punctipennis 
- Elytral punctation less coarse and less dense. Character combination different.

23. Abdomen distinctly bicoloured; tergites III-V reddish and tergites VI-VII extensively black (Assing 2016a: figure 112). Elytra distinctly bicoloured with the anterior portion reddish and the posterior portion sharply black (Assing 2016a: figure 56). Punctation of elytra coarse (Assing 2016a: figure 56). Antennomeres IX-X or VIII-X pale-yellowish, sharply contrasting with the black antennomeres IV-VII (Assing 2016a: figure 1). Median lobe of aedeagus as in Assing (2016a: figures 176-177). Myanmar; Vietnam.

malaisei

- Abdomen not distinctly bicoloured.

24

24. Small species; length of forebody $2.1-2.4 \mathrm{~mm}$. Antennomere XI elongate, approximately as long as the combined length of VIII-X (Assing 2017: figures 26, 39). Pubescence inconspicuous, moderately long, suberect, and moderately dense. Median lobe of aedeagus as in Assing (2017: figures 223-224, 234-235). Widespread. gratellus

- Larger species; length of forebody $>2.7 \mathrm{~mm}$. Antennomere XI short and of conical shape, approximately as long as the combined length of IX and X at most. (Assing 2016b: figure185). Pubescence longer, denser, and sub-erect to erect. Species of the $Z$. hirtus group.

25

25. Pronotum with coarse and rather dense punctation (Assing 2017: figure 78). Antennae shorter and with more transverse antennomeres IV-X; antennomeres IV weakly transverse and X more than twice as broad as long (Assing 2017: figure 38). Abdominal tergites VI and VII with very dense and rather fine non-setiferous punctation anteriorly (Assing 2017: figure 16). Median lobe of aedeagus as in Assing (2017: figures 255-256). Sulawesi.

nigrihirtus

- Pronotum with less distinct and less coarse punctation (Assing 2016b: figure 184). Antennae longer and with less transverse antennomeres IV-X; antennomeres IV approximately as long as broad and X less than twice as broad as long (Assing 2016b: figure185). Abdominal tergites VI and VII with distinctly less fine and less dense punctation (Assing 2016b: figure 186). Pubescence of dorsal surface long, dense, and sub-erect to erect; all sternites with long, dense, and erect pubescence. Median lobe of aedeagus as in Assing (2016b: figures 461-462). Bali. wunderlei

26. Legs bicoloured; femora brown to black with the bases of the meso- and metafemora yellow. Forebody of uniformly

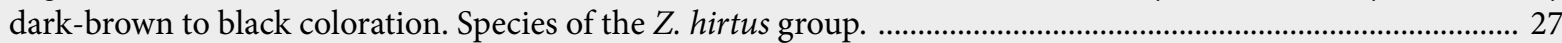

- Legs of uniformly yellowish coloration. 28

27. Smaller species; length of forebody $2.8 \mathrm{~mm}$. Antennae shorter, $1.7 \mathrm{~mm}$ long; antennomere IV weakly transverse; antennomeres IX-X more than twice as broad as long (Assing 2015: figure 57). Abdomen partly brownish. Male sexual characters unknown. Vietnam.

funestus

- Larger species; length of forebody 3.6-3.7 mm. Antennae 2.4-2.5 mm long; antennomere IV noticeably oblong; antennomeres IX-X less than twice as broad as long (Figs 11-12). Abdomen black, except for the brown posterior margins of tergites VII and VIII (Fig. 49). Median lobe of the aedeagus as in Figs 96-97. Vietnam, Laos.

hirtiventris

28. Pronotum and elytra with very sparse and fine punctation; interstices on elytra on average more than twice as broad as diameter of punctures (Fig. 24). Median lobe of aedeagus as in Figs 56-57. Java. facundus

- Pronotum and elytra with much denser and usually also coarser punctation. 29

29. Abdomen bicoloured with segments III-V or III-VI reddish and VI-VIII or VII-VIII extensively infuscate. For Z. quasar from Vietam with a posteriorly somewhat infuscate tergite V (Assing 2016b: figure 180) follow this alternative.

- Abdomen of uniformly reddish or blackish coloration, or reddish with tergite VI (and sometimes also the anterior portion of tergite VII weakly) infuscate.

30. Pronotum with fine and sparse punctation; dorsal surface smooth, not impressed, except for the usual posteromedian impression.

- Pronotum with coarse and rather dense, or coarse and very irregularly distributed punctation; in the latter case pronotum with uneven surface (punctation situated in more or less pronounced impressions).

31. Antennomere XI strongly elongate, at least as long as, usually longer than the combined length of antennomeres VIII-X (Assing 2016a: figure 43). Median lobe of aedeagus as in Assing (2016a: figures 272-273). Widespread. 
- Antennomere XI shorter, shorter than the combined length of antennomeres VIII-X (Assing 2016b: figure 179). Median lobe of aedeagus as in Assing (2016b: figures 457-458). Vietnam. quasar

32. Pronotum strongly transverse, nearly 1.3 times as broad as long and 1.2 times as broad as head; surface without distinct impressions (except for the usual postero-median impression); punctation dense and rather coarse (Assing 2017: figure 68). Abdominal tergite VI reddish or brown with reddish margins (Assing 2017: figure 102). Median lobe of aedeagus with conspicuously short ventral process (Assing 2017: figures 203-204). Thailand. brevilobatus

- Pronotum less transverse, 1.15-1.20 times as broad as long; surface smooth or uneven. Abdominal tergites VI reddish and VII-VIII extensively infuscate.

33. Pronotum with uneven surface; punctation conspicuously irregularly distributed and situated in more or less pronounced impressions (Assing 2017: figure 67). Antennae more slender; antennomere XI elongate, approximately as long as the combined length of VIII-X (Assing 2017: figures 30-31). Median lobe of aedeagus as in Assing (2017: figures 198-199). Thailand; Laos. novinversus

- Pronotum with smooth surface; punctation moderately irregularly distributed (Assing 2016a: figure 172). antennae less slender; antennomere XI shorter, barely as long as the combined length of IX and X (Assing 2016a: figure 173) Median lobe of aedeagus as in Assing (2016a: figures 231-232). Widespread. bettotanus

34. Abdomen predominantly reddish, sometimes with tergite VI and the anterior portion of tergite VII more or less distinctly infuscate.

- Abdomen predominantly black. 40

35. Small species of variable coloration; length of forebody $2.1-2.4 \mathrm{~mm}$. Antennomere XI elongate, at least as long as the combined length of antennomeres VIII-X (Assing 2017: figures 26, 39). Forebody with fine punctation. Median lobe of aedeagus as Assing (2017: figures 222-223, 234-235). Widespread. gratellus

- Larger species; length of forebody $>2.5 \mathrm{~mm}$. Antennomere short and of conical shape, shorter than the combined length of IX and X. Body with long pubescence. Species of the Z. hirtus group. 36

36. Forebody dark-brown to black (Fig. 33). Body of larger average size; length of forebody 3.0-3.5 mm. Abdomen with more extensive and coarser non-setiferous punctation on tergites VI and VII (Fig. 48). Median lobe of aedeagus larger, 0.83-0.90 mm long, and shaped as in Figs 90-91, 93-94. Peninsular Malaysia. hlavaci

- Forebody reddish to dark-brown. Body of smaller average size, 2.6-3.2 mm. Abdomen with finer and less extensive non-setiferous punctation on tergites VI and VII. Median lobe of aedeagus $<0.80 \mathrm{~mm}$ long and of different shape.

37. Slightly larger species; length of forebody 3.0-3.2 mm. Abdominal tergite VI infuscate. Median lobe of aedeagus very broad in ventral view (Assing 2017: figures 229-230). Borneo. parahirtus

- Smaller species; length of forebody 2.6-3.1 mm. Abdominal tergite VI not distinctly infuscate. Median lobe of aedeagus more slender in ventral view.

38. Ventral process of aedeagus distinctly angled subapically in lateral view (Figs 99-100). Peninsular Malaysia. ........ .. lunatus

- Ventral process of aedeagus not angled subapically in lateral view. Sunda Islands. 39

39. Aedeagus with more slender ventral process both in lateral and in ventral view and with more prominent crista apicalis (Figs 73-74). Java. flavorufus

- Aedeagus with less slender ventral process and with broader, less prominent crista apcialis (Figs 63-64). Borneo. matangensis

40. Antennomere XI elongate, approximately as long as the combined length of antennomeres VIII-X. Pronotum rather small in relation to head, only slightly broader than head.

- Antennomere XI shorter, approximately as long as the combined length of antennomeres IX-X. Pronotum relatively larger, much broader than head.

41. Antennae more slender (Assing 2017: figures 28-29). Pronotum with very uneven surface; punctation strongly irregular and situated in more or less pronounced impressions (Assing 2017: figure 65). Male tergite VIII with four blunt projections posteriorly (Assing 2017: figure 196). Median lobe of aedeagus as in Assing (2017: figures 191-194). Widespread (Assing 2017: map 6). proximus 
- Antennae less slender (Assing 2017: figure 33). Pronotum without impressions and with less irregularly distributed punctation (Assing 2017: figure 69). Male tergite VIII only with a median pair of more acute projections posteriorly (Assing 2017: figure 206). Median lobe of aedeagus as in Assing (2017: figures 208-211). Thailand. parvicollis

42. Body rather large (length of forebody 3.4-3.7 mm) and of robust shape (Assing 2015: figure 15). Antennae long (2.7-2.9 $\mathrm{mm}$ ) and massive (Assing 2015: figure 16). Elytra bicoloured with the anterior third reddish-yellow and the posterior two-thirds black (Assing 2015: figure 15). Median lobe of aedeagus as in Assing (2015: figures 33-34). North Vietnam.

fansipanicus

- Body less robust and mostly smaller. Antennae less massive, slender in species with antennae of similar length. Elytra often bicoloured, but either more extensively reddish-yellow with infuscate postero-lateral portions or blackish with only the humeral portions reddish or reddish-yellow.

43. Species of more slender habitus (Assing 2016a: figure 81). Antennae more slender with antennomere IV oblong and antennomere $\mathrm{X}$ less than 1.5 times as broad as long (Assing 2016a: figure 24). Punctation of pronotum and elytra moderately dense (Assing 2016a: figure 81). Median lobe of aedeagus as in Figs 78-79 and Assing (2016a: figures 221-222). China, Hong Kong, Laos notaticornis

- Body less slender and with a relatively larger pronotum. Antennae less slender; antennomere X at least 1.5 times as broad as long and antennomere IV usually as long as broad or weakly transverse. Punctation of pronotum and elytra mostly denser.

44. Ventral process of aedeagus very short in relation to basal capsule (Figs 87-88). Pronotum with maximal width near anterior angles, slightly more strongly tapering posteriorly. Laos. parvilobatus

- Aedeagus with distinctly longer ventral process. Pronotum with lateral margins more evenly convex in dorsal view. 45

45. Median lobe of aedeagus with apically longer and more acute ventral process and with longer crista apicalis in lateral view (Assing 2016a: figures 215-216). China: Yunnan; Thailand. caloderoides

- Median lobe of aedeagus with apically shorter and less acute ventral process and with shorter crista apicalis in lateral view. 46

46. Ventral process of aedeagus basally broader in ventral view (Figs 70-71). Elytra practically completely black; anterior margin only very narrowly reddish-yellow (Fig. 25). Tergite VIII anteriorly with longitudinal striae (Fig. 39). Java.

latibasalis

- Ventral process of aedeagus more slender in ventral view (Figs 76-77 and Assing 2016a: figures 193-194). Elytra mostly more extensively reddish-yellow (Assing 2016a: figure 66). China, Laos, Vietnam. wei

\subsection{Descriptions and additional records}

\subsubsection{Sunda Islands}

\section{Zyras (Zyras) gratellus CAMERoN, 1939}

Material examined: Indonesia: $1 \sigma^{\top}$, Jawa Barat, Cianjur, Kebun Raya, Cibodas, 1400 m, flight interception trap, 29.I.-4.II.2004, leg. Maruyama et al. (cMar).

Comment: The holotype of this remarkably variable species was revised by Assing (2017). The currently known distribution ranges from Peninsular Malaysia to Java and Sulawesi.

\section{Zyras (Zyras) punctipennis CAMERon, 1939 (Figs 1, 19, 34)}

Zyras (Zyras) punctipennis CAMERoN, 1939b: $18 \mathrm{f}$.

Type material examined: Holotype : : "F. C. Drescher, G. Tangkoeban Prahoe, 4000-5000 Voet, Preanger, Java, IX.1933 / Z. punctipennis Cam. Type / Holotype / M. Cameron. Bequest. B.M. 1955-147 / Holotypus Zyras punctipennis Cameron, rev. V. Assing 2017” (BMNH).

Comment: The original description is based on a unique holoype from "G. Tangkoeban Prahoe" (CAmeron 1939b).

Additional material examined: Indonesia: 5 우, Kalimantan Tengah, Busang-Rekut confluence, $0^{\circ} 03^{\prime} \mathrm{S}$, $113^{\circ} 59^{\prime} \mathrm{E}$, flight interception trap, VIII.2001, leg. Brendell \& Mendel (BMNH, cAss). 


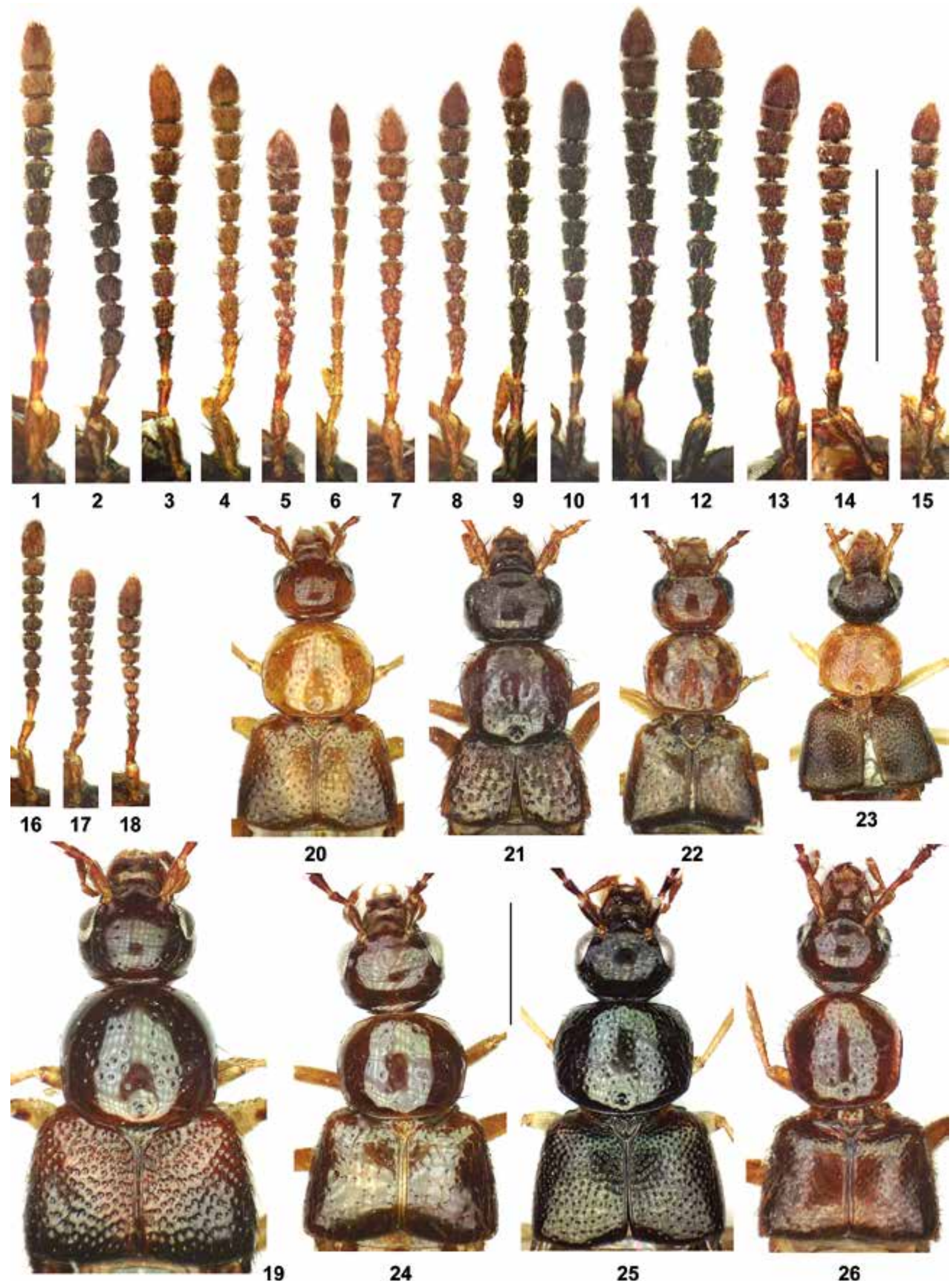

Figs 1-26: Antenna (1-18) and forebody (19-26) of Zyras spp. (1-17, 19-26) and Myrmedonota modiglianii (18): punctipennis, holotype (1, 19); facundus, lectotype $(2,24)$; latibasalis $(3,25)$; kinabaluensis, holotype $(4,21)$; matangensis, holotype $(5,26)$; bryanti, holotype $(6,23)$; granulipennis, holotype (7); flavorufus, lectotype (8); rutrilobatus (9); parvilobatus (10); hirtiventris (11-12; 11: holotype; 12 female paratype); hlavaci (13-14; 13 holotype; 14 paratype from Selangor); lunatus (15); elegantulus, lectotype $(16,20)$; pallipyga, holotype $(17,22)$. Scale bars: $1.0 \mathrm{~mm}$. 


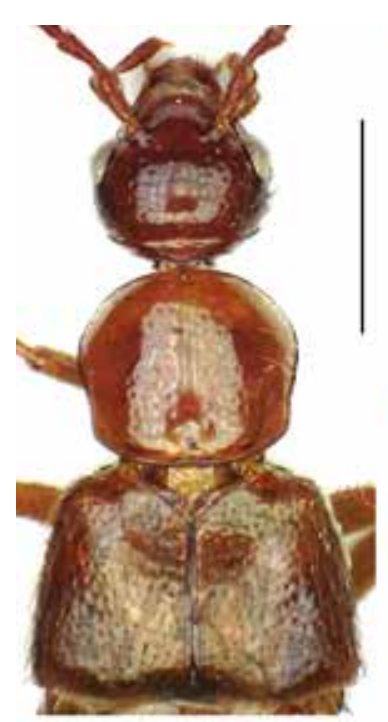

27

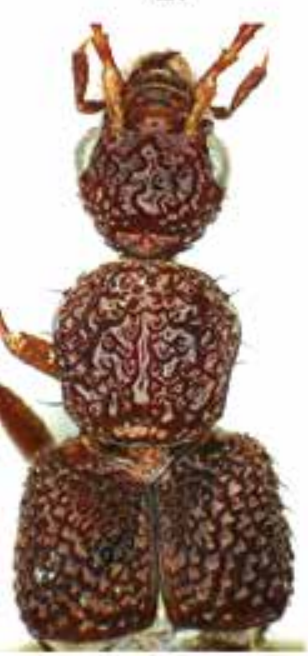

30

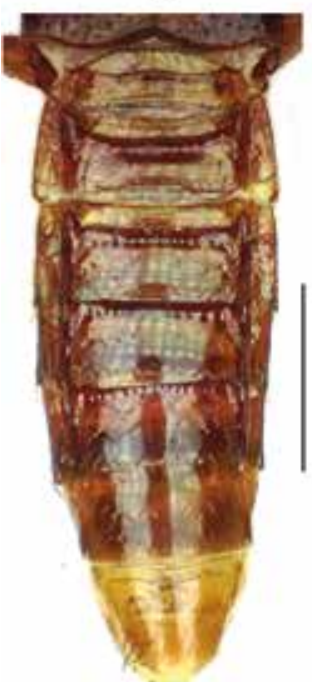

35

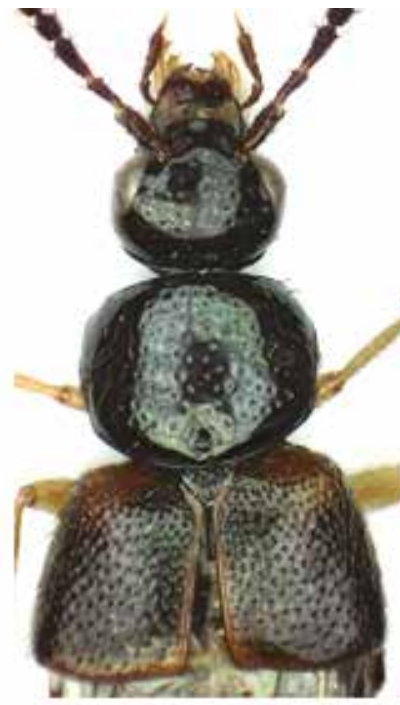

28

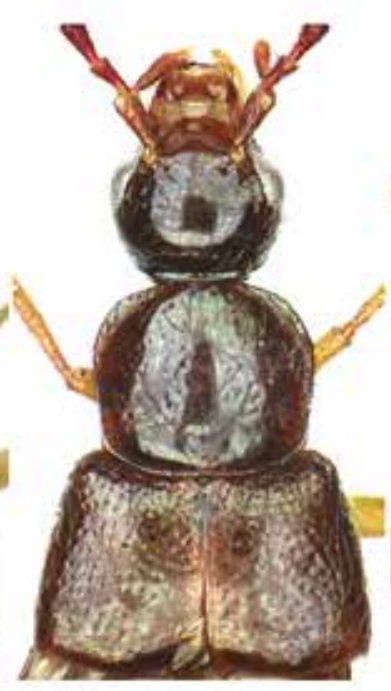

29

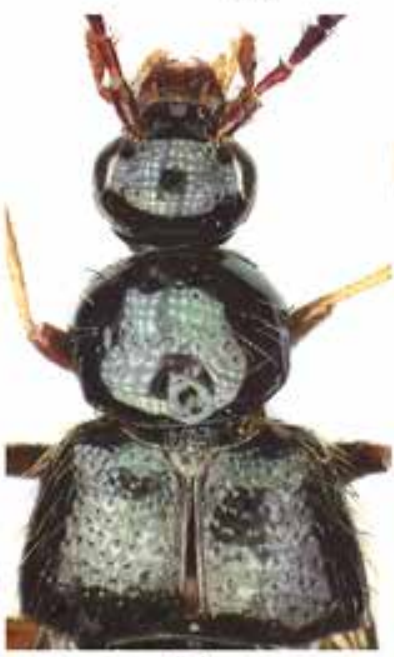

31

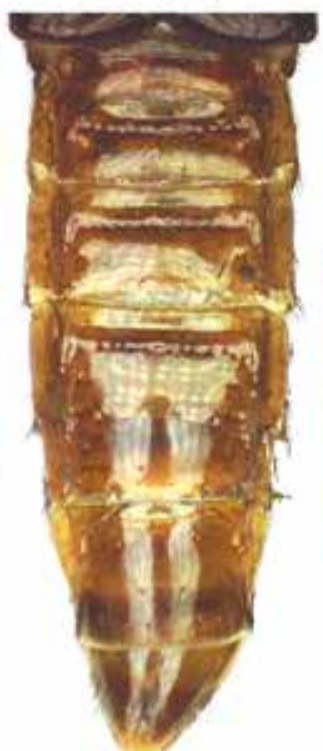

36

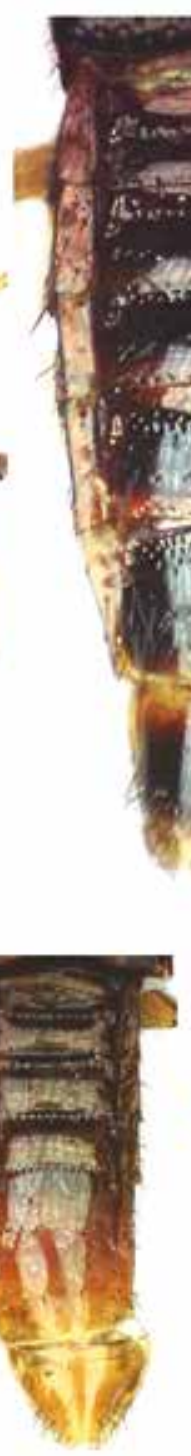

37

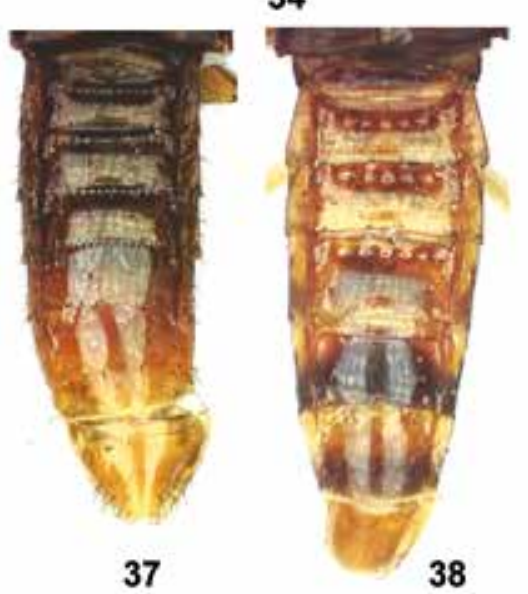

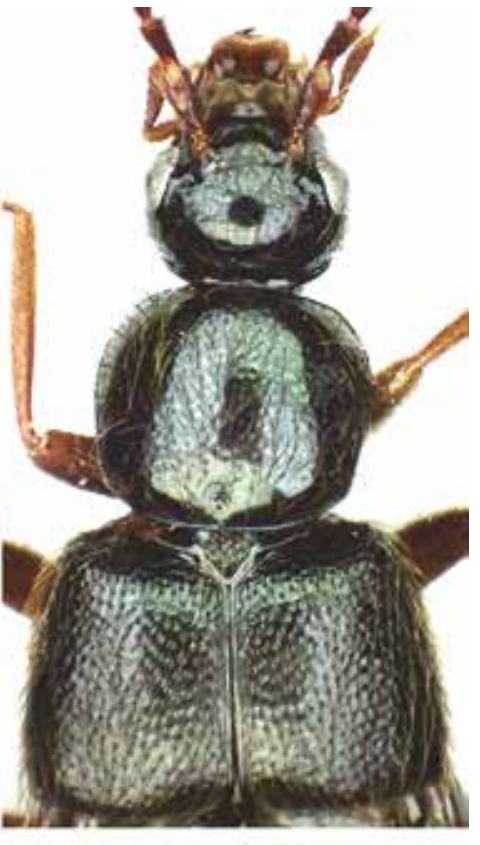

32

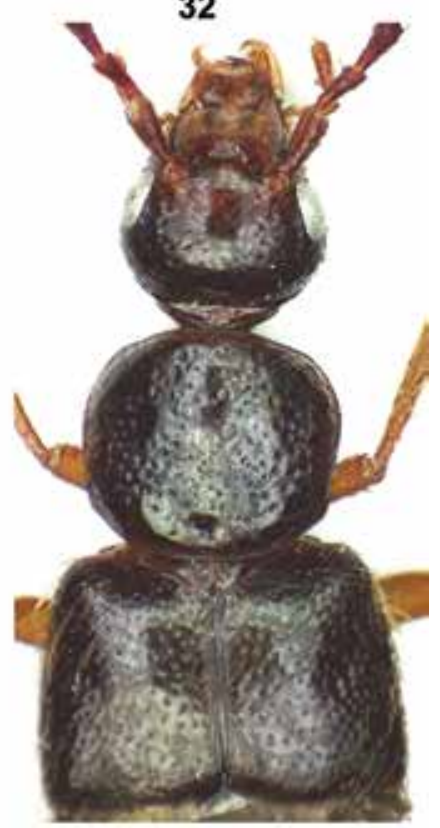

33

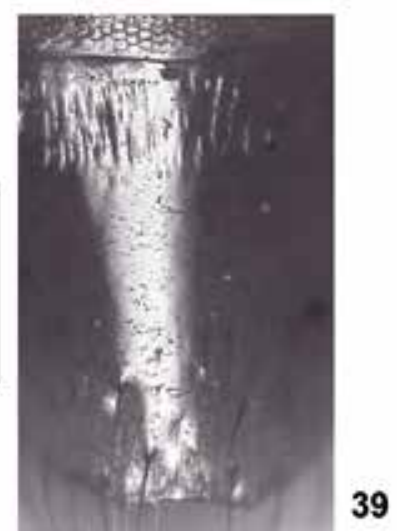

Figs 27-39: Forebody (27-33), abdomen (34-38), and median portion of tergite VIII (39) of Zyras spp.: flavorufus, lectotype (27); parvilobatus (28); lunatus (29); granulipennis, holotype (30); rutrilobatus (31); hirtiventris (32); hlavaci, holotype (33); punctipennis, holotype (34); elegantulus, lectotype (35); facundus, lectotype (36); pallipyga, holotype (37); bryanti, holotype (38); latibasalis (39). Scale bars: 27-38: $1.0 \mathrm{~mm}$; 39: $0.2 \mathrm{~mm}$. 


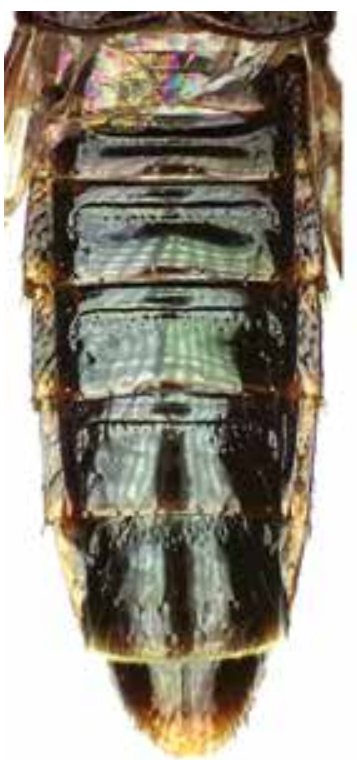

40

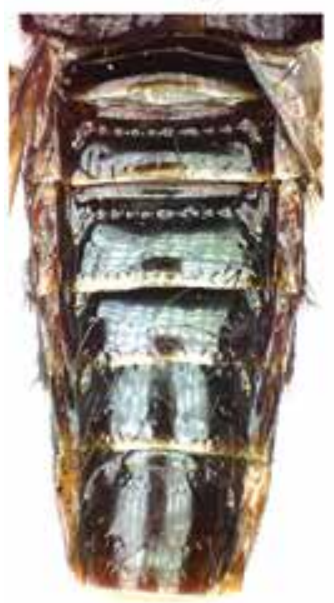

45

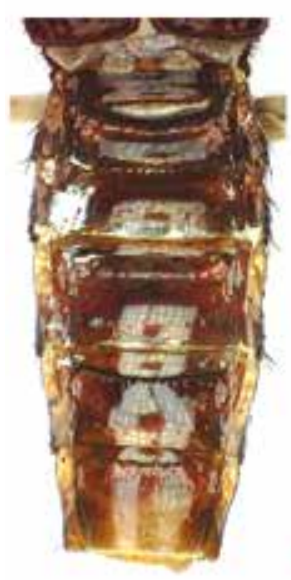

46

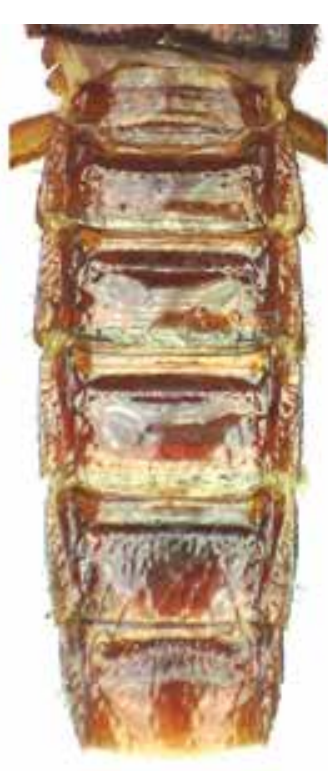

41

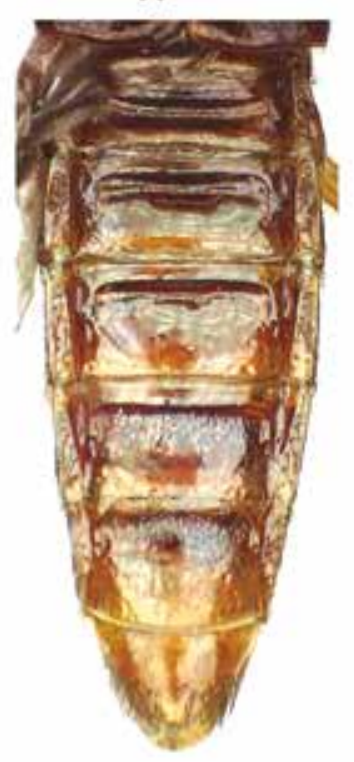

47

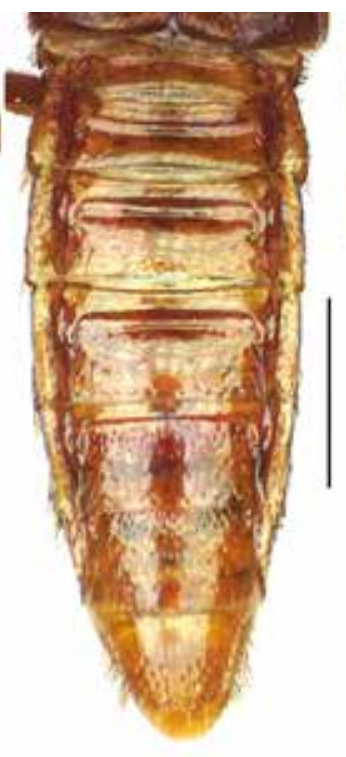

42

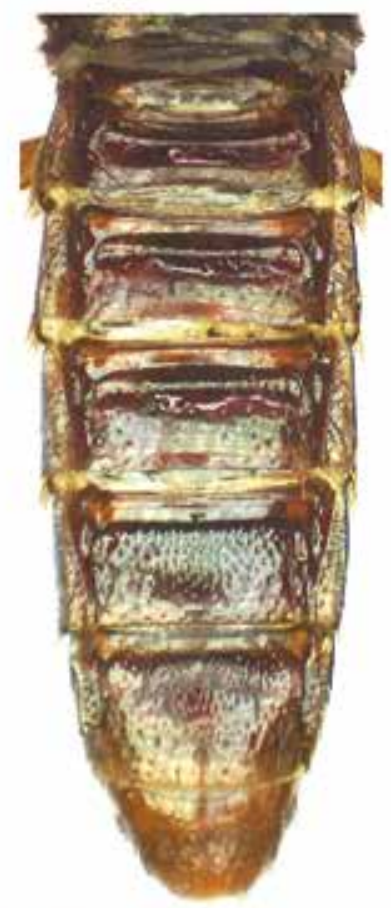

48
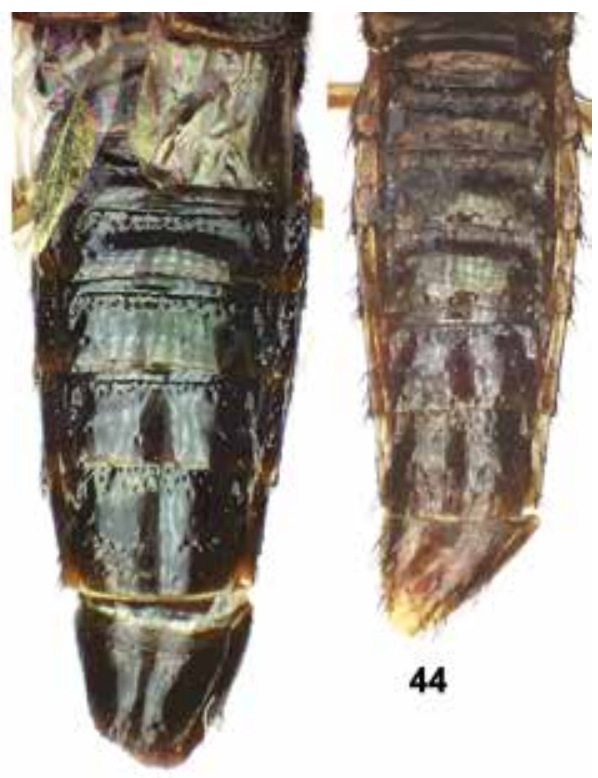

43

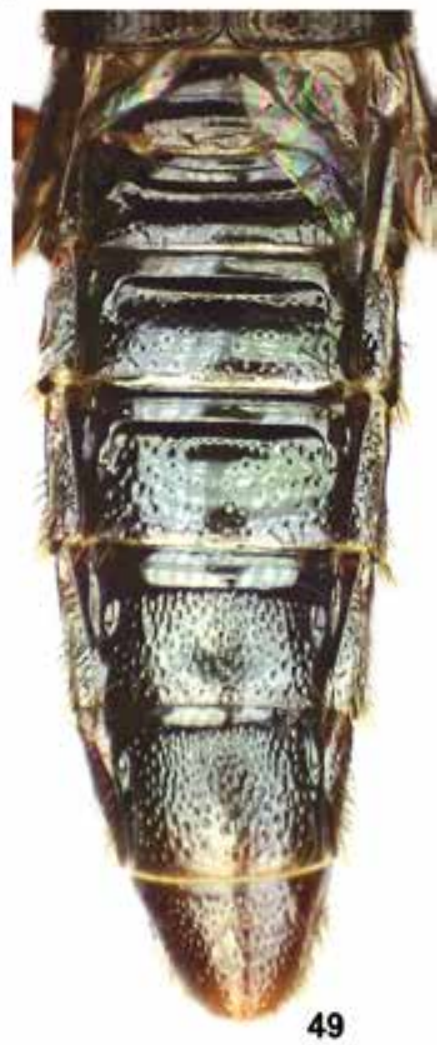

49

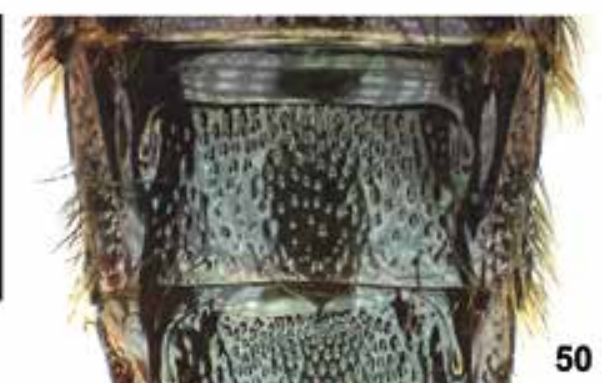
0

51

Figs 40-52: Abdomen (40-49, 52), abdominal tergite VI (50), and forebody (51) of Zyras spp. (40-50) and Myrmedonota modiglianii (51-52): latibasalis (40); matangensis, holotype (41); flavorufus, lectotype (42); parvilobatus (43); kinabaluensis, holotype (44); rutrilobatus (45); granulipennis, holotype (46); lunatus (47); hlavaci, holotype (48); hirtiventris, holotype (49-50). Scale bars:1.0 mm. 


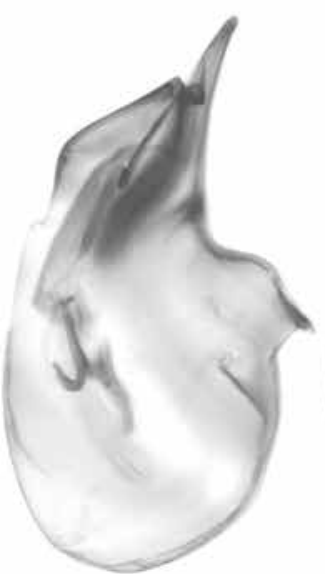

53

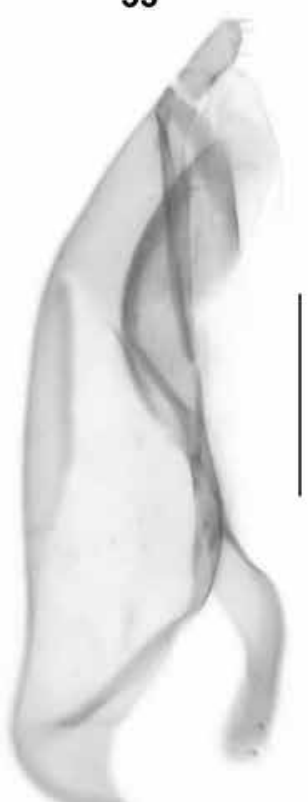

55

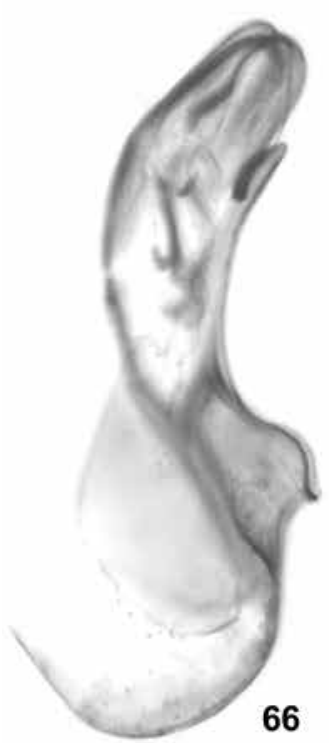

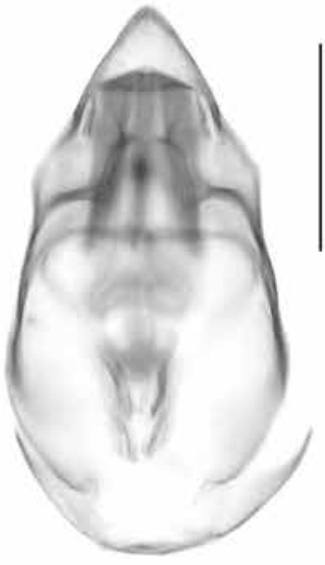

54

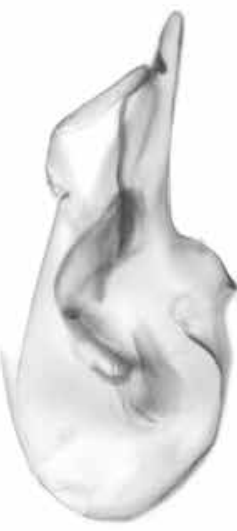

56

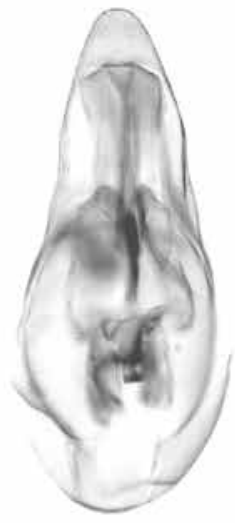

57

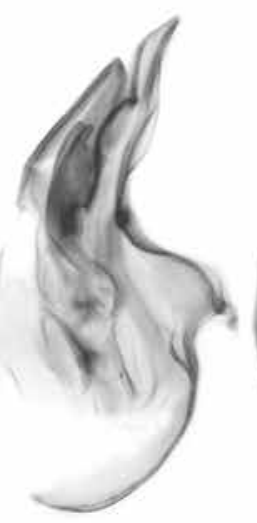

59

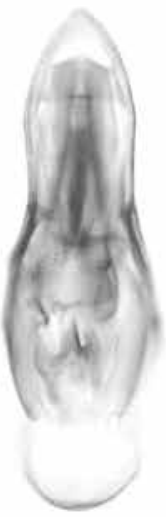

60
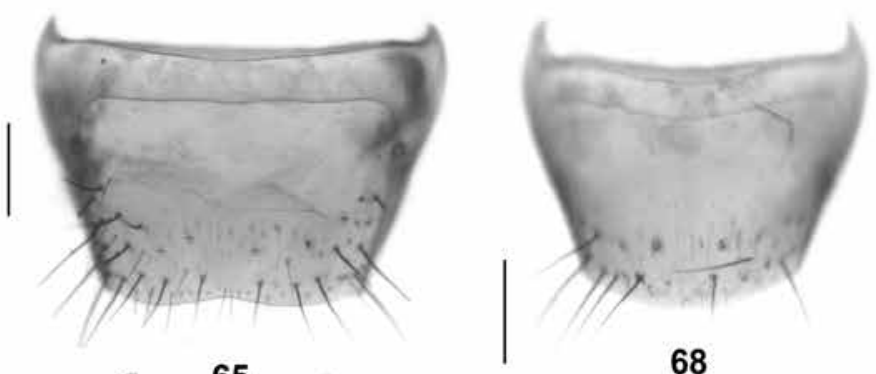

68
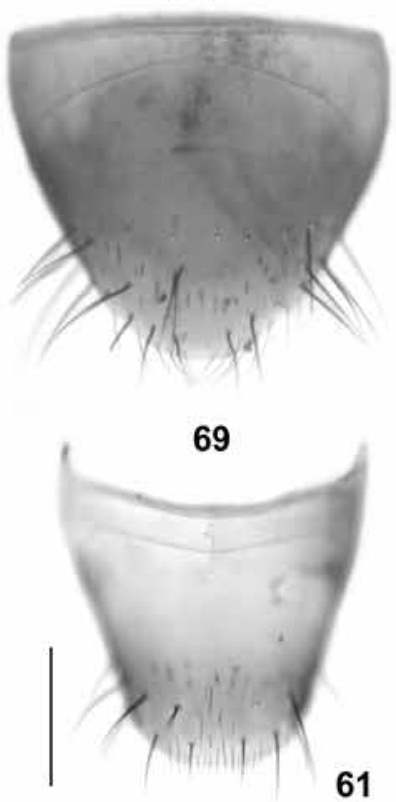

61

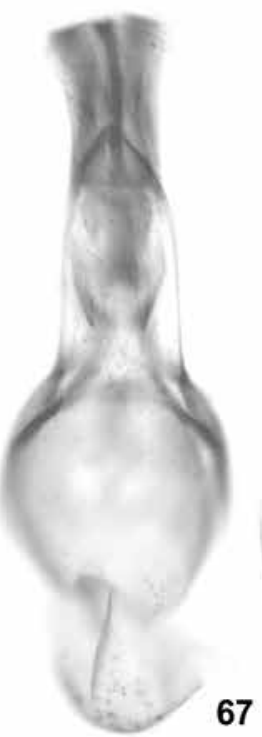

63
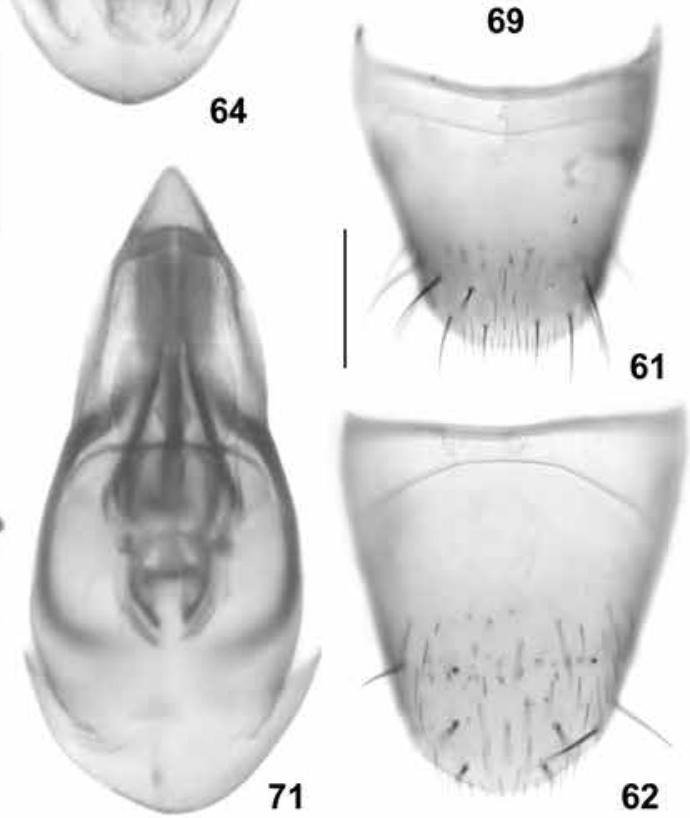

Figs 53-71: Zyras elegantulus, lectotype (53-55), Z. facundus, lectotype (56-58), Z. bryanti (59-62), Z. matangensis, holotype (63-65), Z. granulipennis, holotype (66-69), and Z. latibasalis (70-71): median lobe of aedeagus in lateral and in ventral view $(53-54,56-57,59-60,63-64,66-67,70-71)$; paramere $(55,58)$; male tergite VIII $(61,65,68)$; male sternite VIII $(62,69)$. Scale bars: $0.2 \mathrm{~mm}$. 


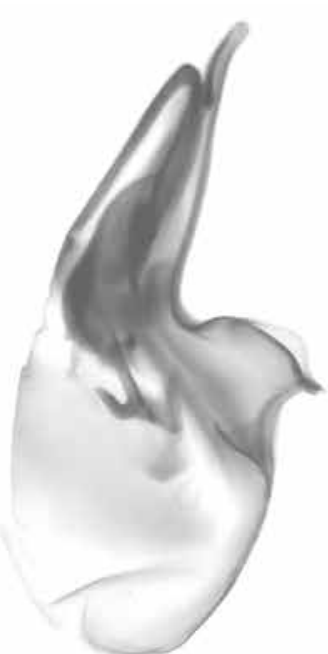

73

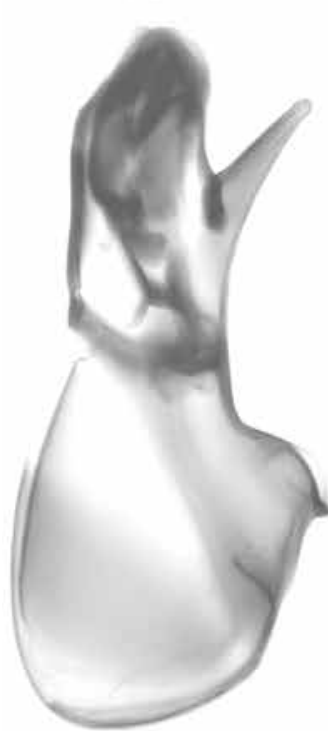

78

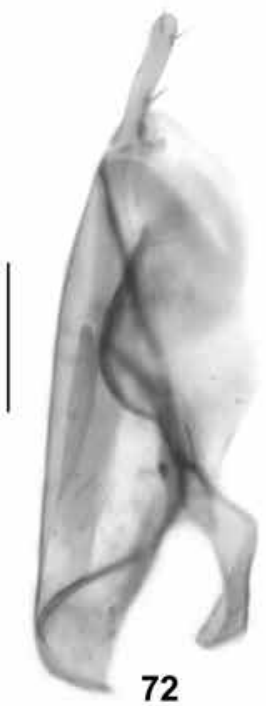

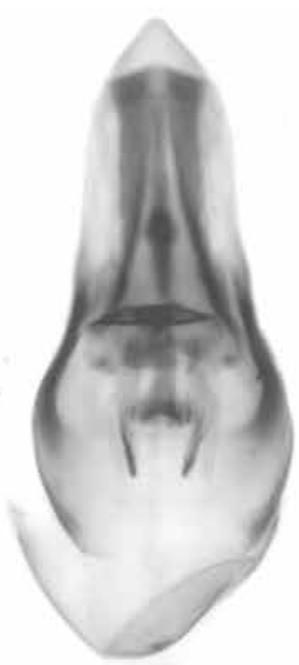

74

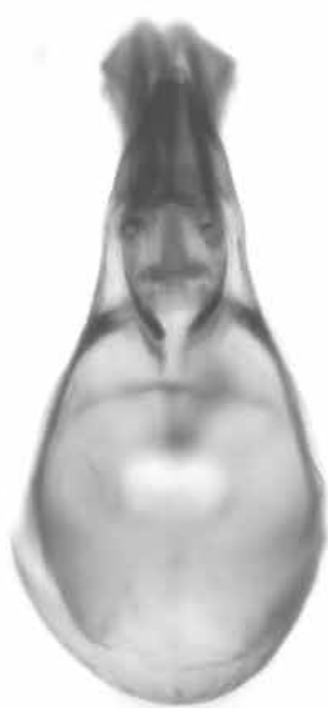

79

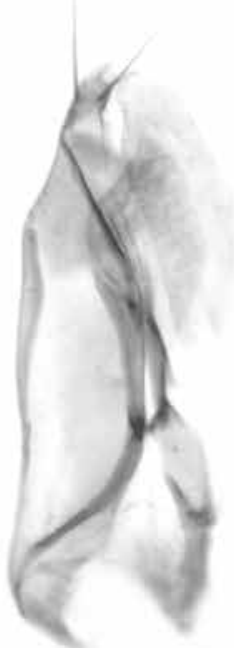

75

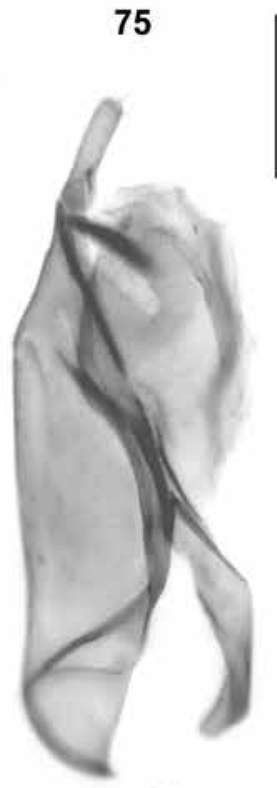

80

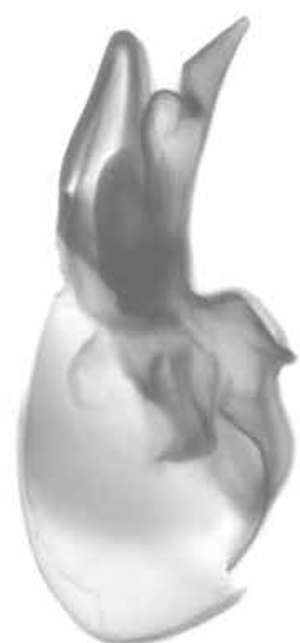

76

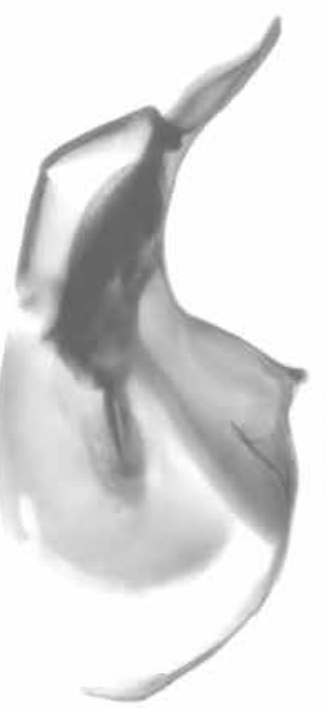

81

82
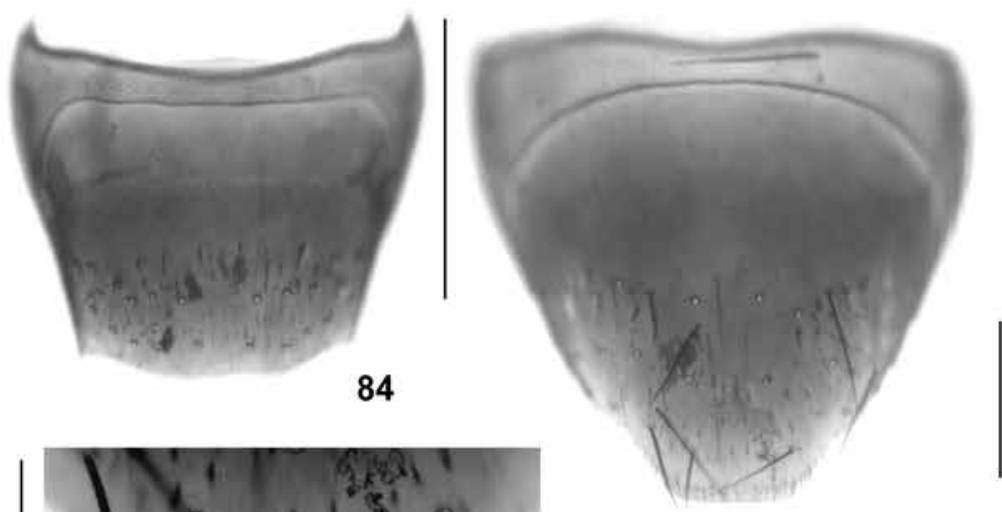

85

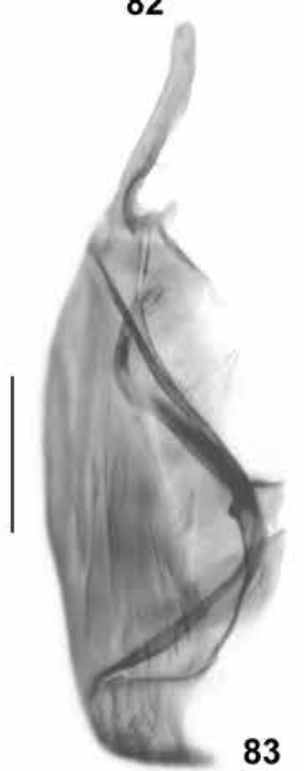

83

Figs 72-86: Zyras latibasalis (72), Z. flavorufus, lectotype (73-75), Z. wei from Laos (76-77), Z. notaticornis from Laos (78-80), and $Z$. rutrilobatus (81-86): paramere $(\mathbf{7 2}, 75,80,83)$; median lobe of aedeagus in lateral and in ventral view $(73-74,76-79,81-82)$; male tergite VIII (84); male sternite VIII (85); postero-median portion of male sternite VIII (86). Scale bars: $84-85$ : $0.5 \mathrm{~mm}$; 72-83: $0.2 \mathrm{~mm}$; $86: 0.1 \mathrm{~mm}$. 


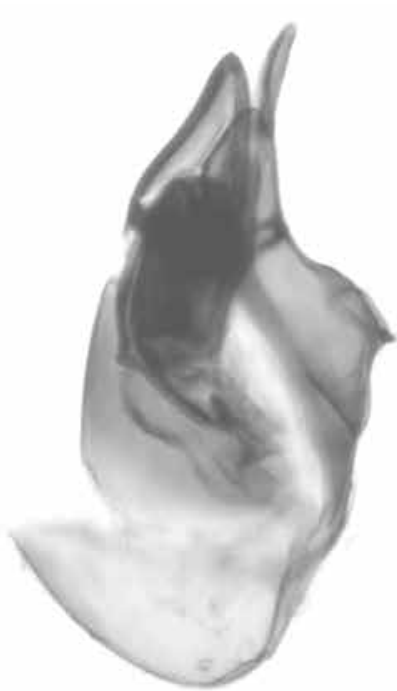

87

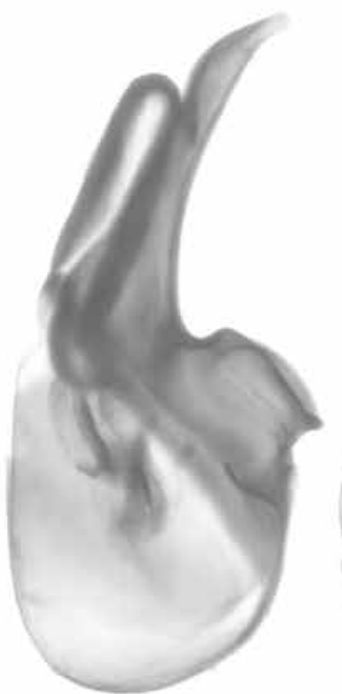

90

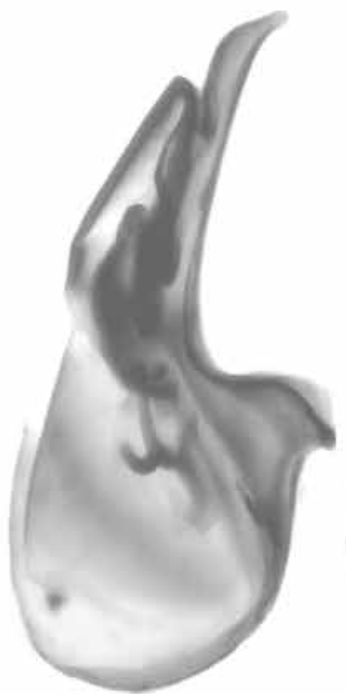

96

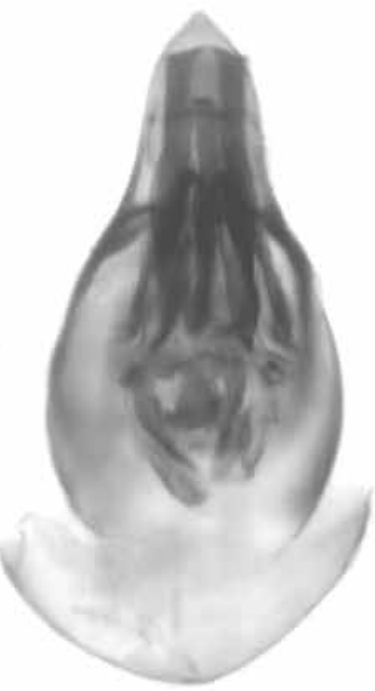

88

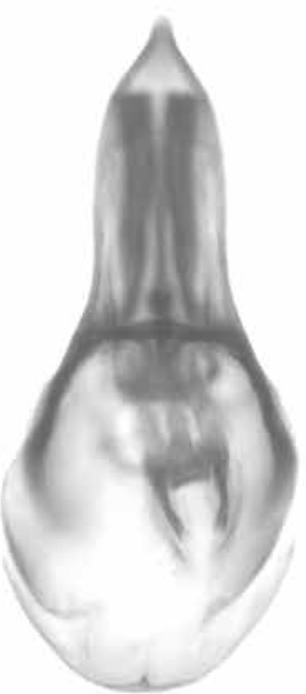

91

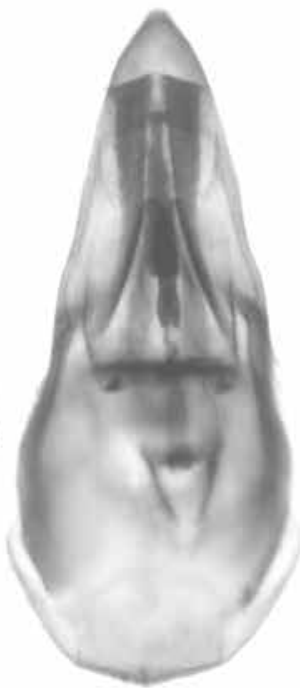

97

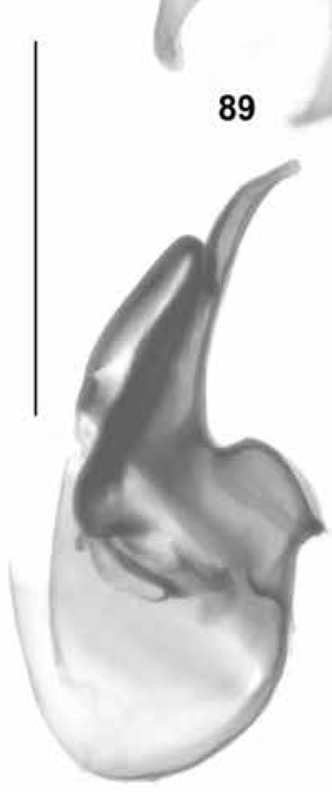

93
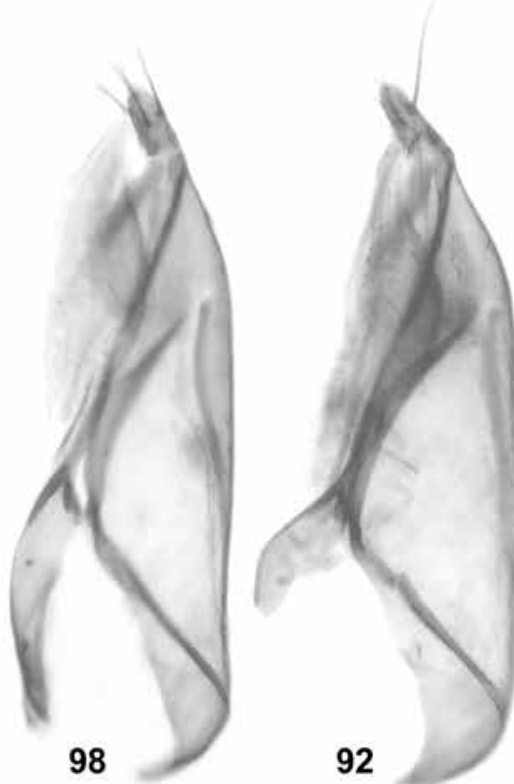

92

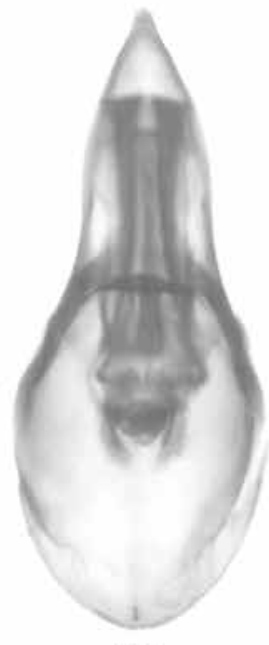

94

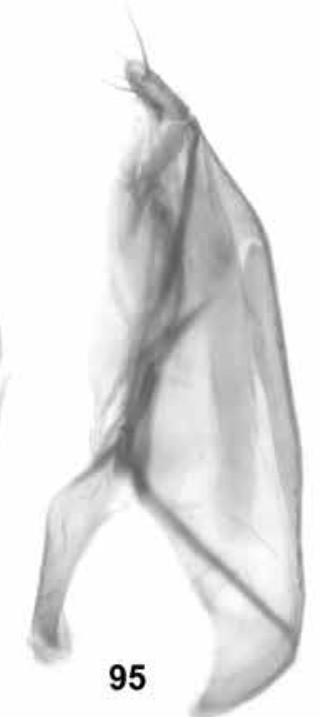

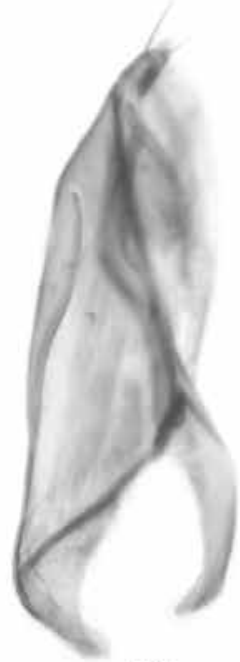

101

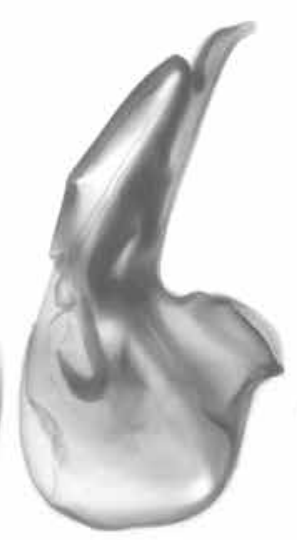

99

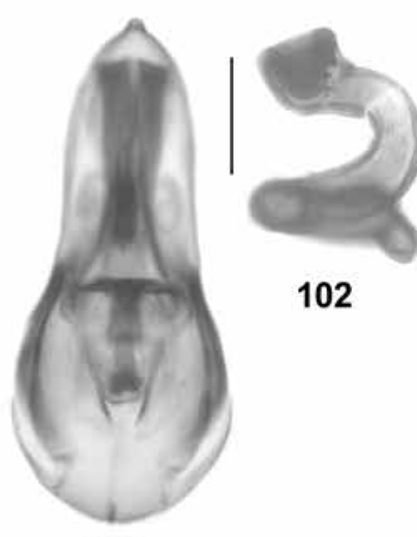

100

Figs 87-102: Zyras parvilobatus (87-89), Z. hlavaci (90-95; 90-92: holotype; 93-95: paratype from Selangor), Z. hirtiventris, holotype (96-98), Z. lunatus (99-101), and Myrmedonota modiglanii (102): median lobe of aedeagus in lateral and in ventral view (87-88, 90-91, 93-94, 96-97, 99-100); paramere (89, 92, 95, 98, 101); spermatheca (102). Scale bars: $87-101: 0.5 \mathrm{~mm}$; 102: $0.1 \mathrm{~mm}$. 
Redescription: Body length $6.5-8.0 \mathrm{~mm}$; length of forebody $3.0-3.4 \mathrm{~mm}$. Coloration: head and pronotum brown; elytra reddish with the postero-lateral portions somewhat infuscate; abdomen dark-brown anteriorly and blackish-brown to blackish posteriorly, with the anterior and posterior margins of the segments reddish; legs pale-yellow, sometimes with the apices of the mesoand metafemora narrowly infuscate; antennae with antennomeres I-II reddish, III-VII or III-VIII brown to blackish-brown, and IX-XI or VIII-XI yellowish; maxillary palpi reddish with the apical palpomere yellowish-red.

Head (Fig. 19) distinctly transverse, median portion extensively impunctate; punctures in lateral portions sparse and rather coarse. Eyes longer than postocular region in dorsal view. Antenna (Fig. 1) 2.2-2.4 mm long; antennomeres IV-VI approximately as long as broad, VII-X increasingly transverse and of gradually increasing width, $\mathrm{X}$ barely 1.5 times as broad as long, and XI rather short, slightly shorter than the combined length of IX and X.

Pronotum (Fig. 19) approximately 1.1 times as broad as long and 1.3 times as broad as head, broadest in anterior half, strongly convex in cross-section; punctation rather coarse, sparse, and irregularly distributed, with impunctate areas on either side of midline; midline broadly impunctate.

Elytra (Fig. 19) $0.75-0.80$ times as long as pronotum; punctation very coarse, defined, very dense near scutellum, gradually becoming less dense towards posterior margin. Hind wings fully developed. Metatarsomere I very long and slender, slightly longer than the combined length of II-IV.

Abdomen (Fig. 34) approximately as broad as elytra, with moderately deep anterior impressions on tergites III-V; anterior impressions of tergites III-V each with a transverse row of dense, coarse, and defined non-setiferous punctures; tergite III with one or two lateral punctures on either side and with twelve setiferous punctures at posterior margin; tergite IV-V with a median pair of punctures, with a short lateral transverse series of three setiferous punctures on either side, and with approximately 15 setiferous punctures at posterior margins; tergite VI with a narrow transverse band of coarse non-setiferous punctures anteriorly, with a median pair of punctures, with a lateral transverse series of three setiferous punctures on either side, and with approximately 15 setiferous punctures at posterior margin; tergite VII with a transverse band of non-setiferous punctures anteriorly and with two transverse series of setiferous punctures in posterior portion, posterior margin with palisade fringe; tergite VIII with setiferous punctures bearing long dark setae in posterior third, posterior margin convex.

$0^{\pi}$ : unknown.

†: posterior margin of sternite VIII broadly concave.

Comparative notes: This species is characterized by relatively large size, its coloration (particularly of the antennae), conspicuously dense and coarse punctation of the elytra, and by the punctation pattern of the abdomen.

Distribution: Zyras punctipennis has been recorded only from the type locality in Java and from one locality in Kalimantan Tengah, Borneo.

\section{Zyras (Zyras) elegantulus CAMERon, 1939}

(Figs 16, 20, 35, 53-55)

Zyras (Zyras) elegantulus CAMERoN, 1939b: 20.

Type material examined: Lectotype $\sigma^{\star}$, present designation: "F. C. Drescher, G. Tangkoeban Prahoe, 4000-5000 Voet, Preanger, Java, 12-18.I.1933 / Syntype / M. Cameron. Bequest. B.M. 1955-147 / Lectotypus ơ Zyras elegantulus Cameron, desig. V. Assing 2017” (BMNH). Paralectotype : "F. C. Drescher, G. Tangkoeban Prahoe, 4000-5000 Voet, Preanger, Java, VII.1934 / Z. elegantulus Cam. Cotype / Syntype / M. Cameron. Bequest. B.M. 1955-147” (BMNH).

Comment: The original description is based on an unspecified number of syntypes from "G. Tangkoeban Prahoe" (CAmeron 1939b). Two syntypes, a male and a female, were located in the Cameron collection. The male is designated as the lectotype.

Redescription: Body length 5.3-5.7 mm; length of forebody $2.5 \mathrm{~mm}$. Coloration (Figs 16, 20, 35): head pale-brown to reddish-brown; pronotum pale-reddish; elytra yellowish to yellowish-red, with the postero-lateral portions more or less extensively infuscate (very extensively so in the paralectotype); abdomen pale-reddish to dark-reddish, with the posterior halves of tergites V-VII darker; legs pale-yellowish; antennae dark-brown with antennomeres I-II pale-reddish to reddish-brown and $\mathrm{X}$-XI yellowish-brown to brown; maxillary palpi reddish with the apical palpomere yellowish.

Head (Fig. 20) moderately transverse, median portion extensively impunctate; punctures in lateral portions sparse and coarse. Eyes longer than postocular region in dorsal view. Antenna (Fig. 16) approximately $1.5 \mathrm{~mm}$ long; antennomeres IV-X transverse, of gradually increasing width and increasingly transverse, $\mathrm{X}$ approximately twice as broad as long, and XI approximately as long as the combined length of IX and X.

Pronotum (Fig. 20) large in relation to head, 1.151.18 times as broad as long and 1.36-1.43 times as broad as head, broadest near anterior angles, moderately convex in cross-section; punctation rather coarse, sparse, and very irregularly distributed, with extensive impunctate areas on either side of midline; midline broadly impunctate.

Elytra (Fig. 20) 0.75-0.79 times as long as pronotum; punctation variable, moderately coarse to coarse, 
moderately sparse to moderately dense, defined, sparser posteriorly than anteriorly. Hind wings present. Metatarsomere I slender, slightly to distinctly shorter than the combined length of II-IV.

Abdomen (Fig. 35) narrower than elytra, with deep anterior impressions on tergites III-V; anterior impressions of tergites III-V each with a transverse row of weakly defined non-setiferous punctures; tergite III with two lateral punctures on either side and with approximately 15 setiferous punctures at posterior margin; tergite IV-V with a median pair of punctures, with 3-5 lateral setiferous punctures on either side, and with approximately 20 setiferous punctures at posterior margins; tergite VI with a narrow transverse row of coarse non-setiferous punctures anteriorly, with a median pair of punctures, with a lateral transverse series of three setiferous punctures on either side, and with approximately 20 setiferous punctures at posterior margin; tergite VII with a narrow transverse band of non-setiferous punctures anteriorly and with two transverse series of setiferous punctures in posterior portion, posterior margin with palisade fringe; tergite VIII with few setiferous punctures bearing long black setae only near posterior margin, posterior margin convex, in the middle truncate or indistinctly concave.

$\mathrm{o}^{7}$ : posterior margin of sternite VIII convex; median lobe of aedeagus (Figs 53-54) $0.57 \mathrm{~mm}$ long, of compact shape, ventral process short and broad; paramere (Fig. 55) much longer than median lobe, $0.84 \mathrm{~mm}$ long, and with very short apical lobe.

\%: posterior margin of sternite VIII concave in the middle.

Comparative notes: This species is characterized by a rather large pronotum (in relation to head), its coloration, a pronotum with very irregular punctation, the punctation pattern of the abdomen, and by the morphology of the aedeagus.

Distribution: Zyras elegantulus has been recorded only from the type locality in Java.

\section{Zyras (Zyras) facundus LAST, 1969}

(Figs 2, 24, 36, 56-58)

Zyras (Zyras) facundus LAST, 1969: 279.

Zyras (Zyras) semirufus CAMERon, 1939b: 18; preoccupied.

Type material examined: Lectotype $\sigma^{x}$, present designation: "F. C. Drescher, G. Tangkoeban Prahoe, 4000-5000 Voet, Preanger, Java, 20.VII.1930 / Z. semirufa [sic] Cam. Type / Syntype / M. Cameron. Bequest. B.M. 1955-147 / Lectotypus o Zyras semirufus Cameron, desig. V. Assing 2017 / Zyras facundus Last, det. V. Assing 2017” (BMNH). Paralectotype + : same data as holotype (BMNH).
Comment: The original description is based on an unspecified number of syntypes from "G. Tangkoeban Prahoe" (CAMERon 1939b). LAst (1969) replaced Zyras semirufus CAMERON, a name preoccupied by Zyras semirufus (BERNHAUER, 1902) in the subgenus Glossacantha Gemminger \& HAROLD, 1968 (Hlaváč et al. 2011), with the nomen novum $Z$. facundus. Two syntypes were located in the Cameron collection. A male is designated as the lectotype.

Redescription: Body length 6.4-7.6 mm; length of forebody 2.9-3.1 mm. Coloration (Figs 2, 24, 36): forebody dark-brown to blackish-brown; abdomen pale-reddish with the posterior portions of tergites VII and VIII weakly infuscate; legs yellowish; antennae blackish-brown with antennomeres I-III slightly to distinctly paler and XI at least apically slightly paler; maxillary palpi brown to dark-brown with the apical palpomere yellowish.

Head (Fig. 24) distinctly transverse, median portion extensively impunctate; punctures in lateral portions sparse and rather fine to moderately coarse. Eyes longer than postocular region in dorsal view. Antenna (Fig. 2) $2.0 \mathrm{~mm}$ long; antennomeres IV approximately as long as broad, V weakly transverse, VI-X of gradually increasing width and increasingly transverse, $\mathrm{X}$ approximately 1.5 times as broad as long, and XI approximately as long as the combined length of IX and X.

Pronotum (Fig. 24) 1.25-1.26 times as broad as long and 1.16-1.23 times as broad as head, broadest in anterior half, moderately convex in cross-section; punctation rather fine, sparse, and irregularly distributed, with extensive impunctate areas on either side of midline, on either side of the broadly impunctate midline with a series of punctures.

Elytra (Fig. 24) 0.88-0.91 times as long as pronotum; punctation sparse and rather fine, regularly or slightly irregularly distributed. Hind wings present. Metatarsomere I slender, approximately as long as the combined length of II-IV.

Abdomen (Fig. 36) narrower than elytra, with deep anterior impressions on tergites III-V; anterior impressions of tergites III-V each with a transverse row of weakly defined non-setiferous punctures, with a lateral setiferous puncture on either side and with four (tergites III-IV) or six (tergite V) setiferous punctures bearing long black setae near posterior margin; tergite VI with a transverse row of sparse non-setiferous punctures anteriorly, with a lateral setiferous puncture on either side and with six setiferous punctures bearing long dark setae near posterior margin; tergite VII with or without few scattered non-setiferous punctures anteriorly and with two transverse series of setiferous punctures posteriorly, posterior margin with palisade fringe; tergite VIII with setiferous punctures bearing long black setae in posterior twofifths, posterior margin convex, in the middle truncate to convex.

$\sigma^{*}$ : posterior margin of sternite VIII strongly convex; median lobe of aedeagus $0.65 \mathrm{~mm}$ long and shaped as in 
Figs 56-57; paramere (Fig. 58) longer than median lobe, $0.77 \mathrm{~mm}$ long, and with rather large and distinctly flattened apical lobe.

: posterior margin of sternite VIII weakly concave in the middle.

Comparative notes: Zyras facundus is characterized by rather massive antennae, a rather strongly transverse pronotum with distinctive punctation, rather sparse and fine punctation of the elytra, the coloration and punctation pattern of the pronotum, and by the morphology of the aedeagus. Regarding the modifications of the apical lobe of the paramere, this species is similar to Z. ambulans Assing, 2017 from Thailand, from which it is distinguished by completely different coloration and much longer elytra alone.

Distribution: Zyras facundus is currently known only from the type locality in Java.

\section{Zyras (Zyras) latibasalis spec. nov.

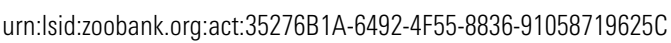 (Figs 3, 25, 39-40, 70-71)}

Type material examined: Holotype ơ: "INDONESIA: Jawa Barat, Cianjur, Kebun Raya, Cibodas (1400 m alt.), 29.I.-4.II.2004 (FIT), Maruyama M. et al. / Holotypus o Zyras latibasalis sp. n., det. V. Assing 2017" (cMar). Paratypes: 9 exs.: same data as holotype (cMar, cAss).

Additional material: 1 : :NE-LAOS: Hu Phan prov., Ban Saluei, Pu Phan mts., $20^{\circ} 15^{\prime} \mathrm{N}, 104^{\circ} 02^{\prime} \mathrm{E}, 1500-2000 \mathrm{~m}$, 2.IV.-11.V.2001, leg. D. Hauck” (NMP).

Etymology: The specific epithet (with broad base) is an adjective alluding to the basally broad ventral process of the aedeagus in ventral view, the most prominent character distinguishing this species from the similar Z. wei.

Description: Body length 5.5-7.0 mm; length of forebody $2.5-3.0 \mathrm{~mm}$. Coloration (Figs 3, 25, 39): forebody blackish with the humeral and anterior portions of the elytra sometimes narrowly and diffusely paler; abdomen black with the posterior margins of the tergites more or less distinctly paler reddish; legs pale-yellowish; antennae blackish with antennomeres IX-X often paler brown (X more so than IX) and antennomere XI dark-yellowish to pale-reddish; maxillary palpi pale-brown with the apical palpomere yellowish.

Head (Fig. 25) distinctly transverse; punctation moderately coarse and moderately dense; median dorsal portion extensively impunctate. Eyes large, much longer than postocular region in dorsal view. Antenna (Fig. 3) 1.9-2.2 mm long and moderately massive; antennomeres IV-VI approximately as long as broad, VII-X weakly transverse, $\mathrm{X}$ less than 1.5 times as broad as long, and XI approximately as long as the combined length of IX and $\mathrm{X}$.

Pronotum (Fig. 25) strongly transverse, 1.22-1.24 times as broad as long and 1.29-1.36 times as broad as head, broadest near anterior angles; posterior angles weakly, obtusely marked; lateral margins not sinuate in posterior half in dorsal view; punctation moderately coarse and moderately dense, nearly regularly distributed; midline rather narrowly impunctate.

Elytra (Fig. 25) approximately 0.85 times as long as pronotum; punctation rather dense and coarse, slightly denser near scutellum and near suture than in posterior and lateral portions. Hind wings present. Metatarsomere I approximately as long as the combined length of II-IV. Abdomen (Fig. 40) slightly narrower than elytra, with moderately deep anterior impressions on tergites III-V; tergites III-V each with a transverse row or band of rather fine and often sparse non-setiferous punctures in anterior impressions, with a lateral setiferous puncture on either side and with four (tergite III) or 6-8 (tergites IV-V) setiferous punctures at posterior margins; tergite VI with a narrow transverse band or a transverse row of rather fine non-setiferous punctures anteriorly, with a lateral setiferous puncture on either side, and with usually eight setiferous punctures at posterior margin (individual punctures may be missing, or additional punctures may be present); tergite VII with a transverse band of fine non-setiferous punctures anteriorly and with two transverse rows of setiferous punctures posteriorly, posterior margin with palisade fringe; tergite VIII with setiferous punctures bearing long dark setae only in posterior fourth, anteriorly with a transverse band of oblong microsculpture (microstriae), posterior margin with shallow concavity in the middle (Fig. 39).

$\sigma^{*}$ : posterior margin of sternite VIII broadly truncate in the middle; median lobe of aedeagus (Figs 70-71) $0.70-0.75 \mathrm{~mm}$ long; ventral process broadly triangular in ventral view; parameres approximately $1.0 \mathrm{~mm}$ long, with long and slender apical lobe.

o : posterior margin of sternite VIII shallowly concave in the middle.

Intraspecific variation: The female from Laos is similar to the type series in size, habitus, coloration, and punctation, except that the apical antennomeres are blackish.

Comparative notes: In external characters (size, habitus, punctation, coloration), in the lateral aspect of the ventral process of the aedeagus, and regarding the long apical lobe of the paramere, $Z$. latibasalis strongly resembles the widespread $Z$. wei. It is distinguished from this species (and from the similar Z. parvilobatus) by the darkyellowish antennomere XI, by the presence of an anterior transverse band of microstriae on tergite VIII, and by the morphology of the aedeagus ( $Z$. wei: ventral process much more slender and basally somewhat constricted in ventral view, and smoothly curved in lateral view; crista apicalis more prominent). 
Distribution: The type locality is situated in Jawa Barat at an altitude of $1400 \mathrm{~m}$. The tentative record from Laos requires confirmation based on males. The type specimens were collected with flight interception traps.

\section{Zyras (Zyras) castaneus (Motschulsky, 1861)}

Material examined: Thailand: 1 ex., Nan distr., Ban Boluang env., $19^{\circ} 08^{\prime} \mathrm{N}, 101^{\circ} 09^{\prime} \mathrm{E}, 650 \mathrm{~m}, 15-25 . \mathrm{V} .2002$, leg. Pacholátko \& Peša (MZMB). Malaysia: $10^{\star}, 1$ i , 1 ex. [all identified by Pace as Z. adulescens], Sabah, Mount Kinabalu National Park, Poring Hot Springs, 480-510 m, 30.VIII.1988 [B163], leg. Smetana (MHNG).

Comment: This widespread species had already been recorded from several localities in Thailand and Borneo (Assing 2017).

\section{Zyras (Zyras) preangeranus CAMERON, 1939}

Zyras (Zyras) quadriterminalis PACE, 2008: 149 f.; syn. nov.

Type material examined: Holotype ơ: "BORNEO Sabah Mt. Kinabalu Nat. Pk., Poring Hot Spgs, 485 m 29.VIII.88, A. Smetana [B160] / Holotypus Zyras quadriterminalis mihi, det. R. Pace 2000 / Zyras quadriterminalis n. sp., det. R. Pace 2000 / MHNG ENTO 00010010 / Zyras preangeranus Cameron, det. V. Assing 2017” (MHNG).

Comment: The original description of Z. quadriterminalis is based on a unique male from "Borneo, Sabah, Mt. Kinabalu, Poring Hot Springs" (PACE 2008). An examination of the holotype revealed that it is conspecific with the widespread $Z$. preangeranus, one of the most common representatives of the subgenus in the Oriental region (Assing 2017).

\section{Zyras (Zyras) montanus (BeRnHAUER, 1915)}

Zyras (Zyras) variolatus PACE, 2003: 68; syn. nov.

Type material examined: Holotype $\sigma^{*}$ : "MALAYSIA: PAHANG, Bukit Fraser (1000 m), Jeriau Waterfalls, 24/ XI/1987, S. Taiti e L. Bartolozzi / Holotypus Zyras variolatus m., det. R. Pace 1988 / Zyras variolatus sp. n., det. R. Pace 1988 / "La Specola", Firenze, 7751 / Zyras montanus (Bernhauer), det. V. Assing 2017" (MZUF).

Additional material examined: see type material of Z. pervariolosus.

Comment: The original description of $Z$. variolatus is based on a unique male from "Malaysia, Pahang, Jerau Water Falls" (PACE 2003). An examination of the holotype revealed that it is conspecific with $Z$. montanus, a species previously known only from Borneo. The male recently recorded as Z. variolatus from Kelan$\tan$ (Assing 2017) is evidently a specimen at the lower end of the size range of $Z$. montanus and additionally distinguished from other examined specimens by a dark antennomere $\mathrm{X}$.

\section{Zyras (Zyras) nigerrimus CAMERON, 1943}

Zyras (Zyras) nigerrimus CAMERoN, 1943: 142.

Zyras (Zyras) bartolozzii PACE, 2003: 68; syn. $\mathbf{n}$.

Zyras (Zyras) alboterminalis PACE, 2008: 150; syn. $\mathbf{n}$.

Type material examined: Z. nigerrimus: Holotype $q$ : “Borneo, Mt. Poi, 5000' / Z. nigerrimus Cam. Type / M. Cameron. Bequest. B.M. 1955-147. / Syntype / Holotypus Zyras nigerrimus Cameron, rev. V. Assing 2017" (BMNH). Paratype + [without elytra]: "Borneo, Mt. Poi / M. Cameron. Bequest. B.M. 1955-147. / Syntype / Paratypus Zyras nigerrimus Cameron, rev. V. Assing 2017".

Z. bartolozzii: Holotype $\sigma^{\top}$ : "MALAYSIA: PAHANG, Genting Sempah (600 m), 21.XI.1987, S. Taiti e L. Bartolozzi / Holotypus Zyras bartolozzii m., det. R. Pace 1988 / Zyras bartolozzii sp. n., det. R. Pace 1988 / "La Specola", Firenze, 7750 / Zyras nigerrimus Cameron, det. V. Assing 2017” (MZUF).

Z. alboterminalis: Holotype $\sigma^{\star}:$ “ “ / SABAH: Kibongol V., 7 km N Tambunan, 700 m, 20.V.1987, Burckhardt - Löbl / Holotypus Zyras alboterminalis mihi, det. R. Pace 2000 / Zyras alboterminalis n. sp., det. R. Pace 2000 / MHNG ENTO 00010000 / Zyras nigerrimus Cameron, det. V. Assing 2017" (MHNG). Paratypes: 1 o $^{\star}$ : "BORNEO SABAH Mt. Kinabalu Nat. Pk., Poring Hot Springs 480 m, 10.V.87 A. Smetana" (MHNG); 1 o': "SABAH: Poring Hot Springs, Langanan Falls, 900-950 m, 12.V.1987, Burckhardt - Löbl” (MHNG).

Additional material examined: Malaysia: $3 \sigma^{\top} \sigma^{*}$, Sarawak, 4th Division, Gn. Mulu NP, alluvial forest litter, V-VII.1978, leg. Hammond \& Marshall (BMNH, cAss).

Comment: The original description of $Z$. nigerrimus is based on material from "Mt. Poi, altitude 5,000 ft." In stating "Type in my collection" CAMERon (1943) designated a holotype. Two type specimens, the holotype and a paratype in poor condition, both females, were located in the Cameron collection. A comparison of the types of Z.nigerrimus with those of Z. alboterminalis and $Z$. bartolozzii revealed that all of them are conspecific. Zyras alboterminalis had already been synonymized with Z. bartolozzii by Assing (2017). In consequence, both Z. alboterminalis and Z. bartolozzii are placed in synonymy with $Z$. nigerrimus.

This species is highly similar to Z. brignolii (PACE, 1986), whose male sexual characters are unknown. Based on 
external characters, Z. nigerrimus is distinguished from $Z$. brignolii only by more slender antennae (preapical antennomeres oblong, as opposed to transverse in Z. brignolii) and by larger eyes.

\section{Zyras (Zyras) kinabaluensis PACE, 2008}

(Figs 4, 21, 44)

Zyras (Zyras) kinabaluensis PACE, 2008: 148.

Type material examined: Holotype $\sigma^{\star}$ : “ $\sigma^{\star} /$ SABAH, Mt. Kinabalu, 1500 m, 21.V.1987, Burckhardt - Löbl / Holotypus Zyras kinabaluensis mihi, det. R. Pace 2000 / Zyras kinabaluensis n. sp., det. R. Pace 2000 / MHNG ENTO 00010003 / Zyras kinabaluensis Pace, det. V. Assing 2017” (MHNG).

Comment: The original description is based on a unique male from "Sabah, Mt. Kinabalu" (PACE 2008).

Redescription: Moderately small species; body length $5.7 \mathrm{~mm}$; length of forebody $2.4 \mathrm{~mm}$. Coloration (Figs 4, 21, 44): body brown with the anterior portions of the paratergites slightly paler; legs yellow with the apical halves of the metafemora slightly darker; antennae and maxillary palpi yellowish.

Head (Fig. 21) moderately transverse, median portion extensively impunctate; punctures in lateral portions coarse and sparse. Eyes moderately large, slightly longer than postocular region in dorsal view. Antenna (Fig. 4) moderately long and rather slender, $2.2 \mathrm{~mm}$ long; antennomeres IV more than 1.5 times as long as broad, V-VIII of gradually decreasing length and decreasingly oblong, VIII weakly oblong, IX approximately as long as broad, $\mathrm{X}$ weakly transverse, and XI short, distinctly shorter than the combined length of IX and X.

Pronotum (Fig. 21) slender, 1.07 times as broad as long and 1.11 times as broad as head, broadest near anterior angles, rather strongly convex in cross-section; lateral margins weakly sinuate in posterior third in dorsal view; posterior angles obtusely marked; punctation dense, coarse, and somewhat irregularly distributed; impunctate median band moderately broad.

Elytra (Fig. 21) very short, 0.65 times as long as pronotum; punctation moderately dense, very coarse, slightly less dense posteriorly than anteriorly. Hind wings completely reduced. Legs long and slender; metatarsomere I slender, nearly as long as the combined length of II-IV.

Abdomen (Fig. 44) slightly broader than elytra, with deep anterior impressions on tergites III-V; anterior impressions of tergites III-V each with a transverse row of distinct non-setiferous punctures, with a lateral puncture on either side, and with six (tergites III and IV) or eight (tergite V) setiferous punctures bearing black setae at or near posterior margin; tergite VI with a narrow transverse band of non-setiferous punctures anteriorly and with two transverse series of setiferous punctures bearing dark setae posteriorly; tergite VII with nonsetiferous punctures anteriorly and with two transverse series of setiferous punctures posteriorly, posterior margin with narrow palisade fringe; tergite VIII with setiferous punctation only in posterior third, posterior margin convex.

$\sigma^{7}$ : median lobe of aedeagus $0.75 \mathrm{~mm}$ long; ventral process of distinctive shape, rather broad in ventral view (PACE 2008: figures 98-99); paramere $0.85 \mathrm{~mm}$ long, apical lobe rather short, flattened and apically broadly convex to obliquely truncate.

†: unknown.

Comparative notes: Based on the slender habitus, the slender antennae, and the morphology of the aedeagus, $Z$. kinabaluensis is closely allied to $Z$. nitens, $Z$. nigerrimus, and related species. It is readily distinguished from all other Zyras sensu strictu species recorded from the Sunda Islands by much shorter elytra, completely reduced hind wings, and by the shape of the median lobe of the aedeagus. In addition, it is characterized by the coloration of the legs and the antennae and by the punctation pattern of the abdomen.

Distribution: The type locality is situated in Mount Kinabalu (Malaysia: Sabah) at an altitude of $1500 \mathrm{~m}$.

\section{Zyras (Zyras) pallipyga PACE, 2008}

(Figs 17, 22, 37)

Zyras (Zyras) pallipyga PACE, 2008: $150 \mathrm{f}$.

Type material examined: Holotype o: “ㅇ / SABAH: E Mt. Kinabalu, 1150 m, rte Ranau - Kota Kinabalu, 24.V.1987, Burckhardt - Löbl / Holotypus Zyras pallipyga mihi, det. R. Pace 2000 / Zyras pallipyga n. sp., det. R. Pace 2000 / MHNG ENTO 00010003 / Zyras pallipyga Pace, det. V. Assing 2017” (MHNG).

Comment: The original description is based on a unique female from "Sabah, E Mt. Kinabalu, ..., Ranau-Kota Kinabalu” (PACE 2008).

Additional material examined: Malaysia: 1 , Sabah, 50 km E Kota Kinabalu, Crocker Mountains, Gg. Emas, 16-27.IV.1993, leg. Jenis (cAss).

Redescription: Small species; body length 4.6-4.8 mm; length of forebody $2.4 \mathrm{~mm}$. Coloration (Figs 17, 22, 37): head and pronotum reddish; elytra yellowish-red, with or without the postero-lateral portions slightly darker; abdomen with segments III-VI reddish to pale reddish-brown and segments VII-VIII yellowish red; antennae brown to dark-brown with antennomeres I-II pale-reddish and XI dark-reddish; maxillary palpi yellowish-red with the apical palpomere yellow. 
Head (Fig. 22) distinctly transverse, median portion extensively impunctate; punctures in lateral portions moderately coarse and sparse. Eyes moderately large, slightly longer than postocular region in dorsal view. Antenna (Fig. 17) short and clavate, $1.20-1.25 \mathrm{~mm}$ long; antennomere IV disc-shaped, approximately twice as broad as long; antennomeres $\mathrm{V}-\mathrm{X}$ disc-shaped, of gradually increasing width and increasingly transverse, $\mathrm{X}$ approximately three times as broad as long, and XI broad and short, approximately as long as the combined length of IX and X.

Pronotum (Fig. 22) distinctly transverse, approximately 1.2 times as broad as long and 1.2 times as broad as head, broadest near anterior angles, moderately convex in cross-section; lateral margins straight in posterior two-thirds in dorsal view; posterior angles weakly marked; punctation sparse, moderately coarse, and irregularly distributed; impunctate median band broad.

Elytra (Fig. 22) approximately 0.9 times as long as pronotum; punctation very sparse and fine, posteriorly even sparser. Hind wings present. Legs relatively short; metatarsomere I rather short, shorter than the combined length of II-IV.

Abdomen (Fig. 37) narrower than elytra, with deep anterior impressions on tergites III-V; anterior impressions of tergites III-V and anterior portion of tergite VI each with a transverse row of defined and not very coarse non-setiferous punctures, with a lateral setiferous puncture on either side, and with numerous fine setiferous punctures at posterior margins; tergites IV-VI additionally with a median pair of coarser setiferous punctures; tergite VII only with scattered and very fine non-setiferous punctures anteriorly and with two transverse series of setiferous punctures bearing long dark setae posteriorly, posterior margin with palisade fringe; tergite VIII with setiferous punctation only in posterior fourth, posterior margin convex.

$\sigma^{\star}$ : unknown.

o : posterior margin of sternite VIII distinctly concave in the middle.

Comparative notes: This species is characterized by small size, its coloration, conspicuously clavate and short antennae, very sparse punctation of the pronotum and elytra, and a distinctive punctation pattern of the abdomen (defined non-setiferous punctures present on tergite VI, but not on tergite VII).

Distribution: The currently known distribution is confined to two localities to the east of Mount Kinabalu, Borneo (Malaysia: Sabah). The holotype was collected at an altitude of $1150 \mathrm{~m}$.

\section{Zyras (Zyras) matangensis CAMERON, 1943}

(Figs 5, 26, 41, 63-65)

Zyras (Zyras) daiaccorum PACE, 2008: 152 f.; syn. nov.

Type material examined: Holotype $q$ : "BORNEO Sabah Mt. Kinabalu Nat. Pk., HQ Liwago River, 1490 m 10.VIII.88, A. Smetana [B97] / Holotypus Zyras daiaccorum mihi, det. R. Pace 2000 / Zyras daiaccorum n. sp., det. R. Pace 2000 / MHNG ENTO 00010004 / Zyras matangensis Cameron, det. V. Assing 2017” (MHNG). Paratype + : same data as holotype, but "3.IX.1988 ... [B174]" (MHNG).

Additional material examined: Malaysia: $1 \sigma^{\top}$ [identified as Z. adulescens by Pace], Sabah, Crocker Range, $1600 \mathrm{~m}$, 18.V.1987, leg. Burckhardt \& Löbl (MHNG).

Comment: The original description of Z daiaccorum is based on a female holotype from "Borneo, Sabah, Mt. Kanabalu Nat. Pd., HQ Liwagu River" and three females from the same locality (PACE 2008). An examination of the holotype and a paratype revealed that these specimens are conspecific with the holotype of Z. matangensis, which was revised by Assing (2017). The external and sexual characters of the holotype of $Z$. matangensis are illustrated in Figs 5, 26, 41, 63-65.

\section{Zyras (Zyras) bryanti CAMERON, 1943 \\ (Figs 6, 23, 38, 59-62)}

Zyras (Zyras) bryanti CAMERON, 1943: $141 \mathrm{f}$.

Zyras (Zyras) mortuorum PACE, 1990: 99; syn. nov.

Zyras (Zyras) paederinus PACE, 2008: 153; syn. nov.

Type material examined: Z. bryanti: Holotype $\sigma^{*}$ : "Matang, 22.I.14, 2000 ft / G 28 / Z. bryanti Cam. Type / Holotype / M. Cameron. Bequest. B.M. 1955-147 / Holotypus Zyras bryanti Cameron, rev. V. Assing 2017” (BMNH).

Z. mortuorum: Holotype ơ: "PHILIPPINES, SAGADA, 19/12/79, L. Deharveng / En Aval Village, lavage d'humus / Holotypus Zyras mortuorum m., det. R. Pace 1985 / Zyras mortuorum sp. n., det. R. Pace 1985 / Museum Paris 1998, Coll. J. Orousset / Zyras bryanti Cameron, det. V. Assing 2017" (MNHNP).

Z. paederinus: Holotype ơ: "BORNEO SABAH Mt. Kinabalu N. P., above Poring Hot Springs, 520 m, 9.V.87, A. Smetana / Holotypus Zyras paederinus mihi, det. R. Pace 2000 / Zyras paederinus n. sp., det. R. Pace 2000 / MHNG ENTO 00010006 / Zyras bryanti Cameron, det. V. Assing 2017” (MHNG).

Comment: The original description of $Z$. bryanti is based on a unique holotype from "W. Sarawak: Mt. Matang" (CAMERON 1943), that of $Z$. mortuorum on a male holotype and a male paratype from "environs de Sagada" 
(PACE 1990), and that of $Z$. paederinus on a unique male from "Sabah, Mt. Kinabalu, above Poring Hot Springs" (PACE 2008). An examination of the holotypes of the three names revealed that they are conspecific. Hence the synonymies proposed above. The holotype of $Z$. mortuorum has the antennae somewhat darker (antennomeres III-X dark-brown, distinctly contrasting with the reddish-yellow antennomere XI), more extensively infuscate tergites VI and VII, and the ventral process of the aedeagus slightly more acute in ventral view, but otherwise no evidence was found suggesting that it should represent a distinct species.

Additional material examined: Thailand: 1 , Satun Province, Thale Ban National Park, $20 \mathrm{~km}$ E Satun, 200-400 m, 1-4.I.1996, leg. Schulz \& Vock (cAss). Malaysia: $1 \sigma^{\star}, 1$ ㅇ, Kelantan, Gua Musang, 3.VI.2006, leg. Čiampor (cHla, cAss).

Redescription: Small species; body length 3.8-4.8 mm; length of forebody $1.7-2.1 \mathrm{~mm}$. Coloration (Figs 6 , $23,38)$ : head brown to blackish-brown; pronotum pale-reddish; elytra yellowish red with the posterolateral portions more or less extensively and more or less distinctly, diffusely infuscate (sometimes leaving only the anterior margin and the scutellar portion paler); abdomen yellowish-red with most to nearly all of tergite VI (except for the anterior and antero-lateral portions) and the posterior two-fifths to four-fifths of tergite VII infuscate; antennae yellowish-red to darkbrown with the basal antennomeres dark-yellowish to reddish and antennomere XI reddish-yellow; maxillary palpi yellowish.

Head (Fig. 23) distinctly transverse, median portion extensively impunctate; punctures in lateral portions rather dense and moderately coarse. Eyes large, approximately twice as long as postocular region in dorsal view. Antenna (Fig. 6) long and very slender, 1.7-2.1 mm long; antennomeres IV-VI approximately twice as long as broad (or nearly so), VII-X distinctly oblong, of gradually decreasing length, and decreasingly oblong, and XI approximately as long as the combined length of IX and X.

Pronotum (Fig. 23) 1.08-1.14 times as broad as long and 1.08-1.17 times as broad as head, broadest near anterior angles, weakly convex in cross-section; punctation very dense and fine; midline without impunctate band.

Elytra (Fig. 23) nearly $0.83-0.89$ times as long as pronotum; punctation very dense, slightly coarser than that of pronotum. Hind wings present. Metatarsomere I slender, shorter than the combined length of II-IV.

Abdomen (Fig. 38) narrower than elytra, with deep anterior impressions on tergites III-V; anterior impressions of tergites III-V each with a transverse row of few very large, but weakly defined puncture-like impressions, with a lateral puncture on either side, and with four (tergites III and IV) or six (tergite V) fine setiferous punctures at posterior margin; tergite VI without non-setiferous punctures anteriorly, with a lateral setiferous puncture on either side, and with six setiferous punctures at posterior margin; tergite VII without non-setiferous punctures anteriorly, with two transverse rows each composed of four setiferous punctures posteriorly, posterior margin with palisade fringe; tergite VIII with setiferous punctation only in posterior fourth, posterior margin convex (Fig. 61).

$0^{7}$ : posterior margin of sternite VIII convex (Fig. 62); median lobe of aedeagus (Figs 59-60) nearly $0.5 \mathrm{~mm}$ long; ventral process slender, ventrally with or without a median carina; paramere slightly longer than median lobe, apical lobe very long and with conspicuously long subapical seta.

q : posterior margin of sternite VIII weakly concave in the middle.

Comparative notes: Males of $Z$. bryanti are readily distinguished from all other Zyras sensu strictu species from the Palaearctic and Oriental regions by the morphology of the aedeagus. In addition, this species is characterized by the coloration, small body size, dense punctation of the forebody, the punctation pattern of the abdomen, and the long seta on the apical lobe of the paramere. As can be inferred from the similarly derived punctation of the forebody and the abdomen, as well as from the similarly slender antennae and habitus, Z. bryanti is closely allied to $Z$. densissimus Assing, 2017 from Sulawesi Utara, from which it differs by different coloration (Z. densissimus: whole body of much darker coloration; pronotum blackish), less dense and less fine punctation of the forebody, and a less convex (cross-section) and posteriorly less strongly tapering pronotum (cross-section).

Distribution: Zyras bryanti is currently known from one locality in Borneo, one in Thailand, one in Peninsular Malaysia, and one in the Philippines.

\section{Zyras (Zyras) granulipennis CAMERON, 1930 \\ (Figs 7, 30, 46, 66-69)}

Zyras granulipennis CAMERon, 1930: $167 \mathrm{f}$.

Zyras pervariolosus PACE, 2008: 150; syn. nov.

Type material examined: Z. granulipennis: Holotype $\sigma^{*}$ : "N. Borneo. Bettotan, / Nr. Sandakan. July 24 $4^{\text {th }} 1927 . /$ Zyras granulipennis Cam. Type / Holotype / M. Cameron. Bequest. B.M. 1955-147 / Holotypus Zyras granulipennis Cameron, rev. V. Assing 2017" (BMNH).

Z. pervariolosus: Holotype ơ :BORNEO SABAH Mt. Kinabalu Nat. Pk., HQ at Liwagu Rv., 1500 m 30.IV.1987, A. Smetana / Holotypus Zyras pervariolosus mihi, det. R. Pace 2000 / Zyras pervariolosus n. sp., det. R. Pace 2000 / MHNG ENTO 00010008 / Zyras granulipennis Cameron, det. V. Assing 2017" (MHNG). Paratype क: "SABAH: E Mt. Kinabalu, 1150 m, rte Ranau-Kota Kinabalu, 24.V.1987, Burckhard - Löbl / Paratypus 
Zyras pervariolosus mihi, det. R. Pace 2000 / Zyras pervariolosus n. sp., det. R. Pace 2000 / MHNG ENTO 00010009 / Zyras montanus (Bernhauer), det. V. Assing 2017” (MHNG).

Comment: The original description of $Z$. granulipennis is based on a unique holotype from "North Borneo; Bettotan" (CAMERon 1930), that of $Z$. pervariolosus on a male holotype from "Sabah, Mt. Kinabalu Nat. Pk., HQ at Liwagu Rv." and two female paratypes from "Sabah, E Mt. Kinabalu, ..., rte. Ranau-Kota Kinabalu” (PACE 2008). An examination of the two holotypes revealed that they are conspecific; hence the synonymy proposed above. The examined paratype of $Z$. pervariolosus is conspecific with Z. montanus (BERNHAUER, 1915).

Redescription: Rather small species; body length 6.2-6.4 mm; length of forebody $2.8-2.9 \mathrm{~mm}$. Coloration (Figs 7, 30, 46): forebody dark-brown to black; abdomen: tergites III-VI dark-brown with the anterior and antero-lateral portions paler, tergites VII-VIII reddishbrown; legs with the profemora, the protibiae, and the mesofemora brown, metafemora distinctly bicoloured with the basal two-fifths pale yellowish and the apical three-fifths dark-brown to blackish, meso- and metatibiae pale yellowish with the base narrowly blackish and the apex slightly darker, and the tarsi yellowish; antennae pale-reddish; maxillary palpi dark reddish with the apical palpomere pale-reddish.

Head (Fig. 30) relatively weakly transverse; punctation conspicuously coarsely granulose, along middle of dorsal surface with narrow and irregular glossy elevation. Eyes moderately large, barely longer than postocular region in dorsal view. Antenna (Fig. 7) approximately $2.0 \mathrm{~mm}$ long; antennomeres IV-V oblong, VI approximately as long as broad, VII-X increasingly transverse, $\mathrm{X}$ approximately 1.5 times as broad as long, and XI of conical shape, barely as long as the combined length of IX and X.

Pronotum (Fig. 30) very weakly transverse, 1.03 times as broad as long and 1.18-1.23 times as broad as head, broadest near anterior angles, posteriorly distinctly tapering, strongly convex in cross-section; posterior angles marked; lateral margins sinuate in posterior two-thirds in dorsal view; punctation conspicuously coarsely granulose, in the middle and in lateral portions with irregularly elevated glossy elevations; at lateral and anterior margins with very long and rather stout dark and erect setae.

Elytra (Fig. 30) approximately 0.8 times as long as pronotum; punctation extremely coarsely granulose and very dense. Hind wings present. Metatarsomere I slender, approximately as long as the combined length of II-IV.

Abdomen (Fig. 46) nearly as broad as elytra, with deep anterior impressions on tergites III-V; anterior impressions of tergites III-V each with a transverse row of very fine and weakly defined puncture-like impressions, with a lateral puncture on either side, and with a transverse series of eight setiferous punctures near posterior margin; tergite VI with a transverse row of few fine non-setiferous punctures anteriorly, with a lateral setiferous puncture on either side, and with eight setiferous punctures near posterior margin; tergite VII with sparse non-setiferous punctures in antero-median portion and with two transverse rows each composed of few setiferous punctures posteriorly, posterior margin with palisade fringe; tergite VIII with setiferous punctation bearing long and rather stout black setae in posterior third, posterior margin weakly convex in the middle (Fig. 68).

$\sigma^{*}$ : sternite VIII with strongly convex posterior margin (Fig. 69); median lobe of aedeagus $0.72 \mathrm{~mm}$ long and shaped as in Figs 66-67; parameres malformed in the holotype.

o: unknown.

Comparative notes: This highly distinctive species is easily distinguished from all its consubgeners based on the conspicuous punctation of the forebody alone, particularly the strongly granulose punctation of the elytra. It is additionally characterized by the shape of the pronotum, the coloration of the legs, the punctation pattern of the abdomen, and by the shape of the median lobe of the aedeagus. Among the described species recorded from the Oriental region, Z. granulipennis is most similar to the sympatric $Z$. montanus, from which it additionally differs by smaller body size, more slender head and pronotum, a distinctly more convex and less transverse pronotum with coarser punctation and more pronounced glossy elevations, by shorter antennae with shorter and more transverse antennomeres IV-X and darker apical antennomeres (Z. montanus: antennomeres X-XI paleyellowish), fewer setiferous punctures on the abdomen, and by the shape of the median lobe of the aedeagus.

Distribution: Zyras granulipennis has been recorded only from two localities in Sabah (Borneo), Malaysia.

\section{Zyras (Zyras) flavorufus CAMERon, 1939 \\ (Figs 8, 27, 42, 73-75)}

Zyras (Zyras) flavorufus CAMERON, 1939b: 18.

Type material examined: Lectotype $\sigma^{*}$, present designation: "F. C. Drescher, G. Tangkoeban Prahoe, 4000-5000 Voet, Preanger, Java, IX.1933 / Z. flavorufus Cam. I Syntype / M. Cameron. Bequest. B.M. 1955-147 / Lectotypus ơ Zyras flavorufus Cameron, desig. V. Assing 2017” $(\mathrm{BMNH})$.

Comment: The original description is based on an unspecified number of syntypes from "G. Tangkoeban Prahoe ... 20.VII.30" (CAMERon 1939b). The date indicated on the label of the sole specimen found in the Cameron collection differs from that indicated in the description, but it can be assumed that it is one of the 
specimens that CAMERON (1939b) based his description on and that it has type status (identification label with Cameron's handwriting; collection date six years prior to publication year; characters matching original description). The specimen is designated as the lectotype.

Redescription: Body length $6.7 \mathrm{~mm}$; length of forebody $3.1 \mathrm{~mm}$. Coloration (Figs 8, 27, 42): body reddish with the head and the postero-lateral portions slightly darker; legs dark-yellowish; antennae dark-brown with the basal three antennomeres reddish; maxillary palpi reddish with the apical palpomere yellowish-red.

Head (Fig. 27) moderately transverse; punctation moderately dense and moderately coarse; median dorsal portion extensively impunctate. Eyes moderately large, slightly longer than postocular region in dorsal view. Antenna (Fig. 8) $2.1 \mathrm{~mm}$ long and rather slender; antennomeres IV indistinctly oblong, $\mathrm{V}$ as long as broad, VI-X increasingly transverse and of gradually increasing width, $\mathrm{X}$ less than 1.5 times as broad as long, and XI of conical shape, shorter than the combined length of IX and X.

Pronotum (Fig. 27) 1.11 times as broad as long and 1.21 times as broad as head, broadest in anterior half; posterior angles marked; lateral margins distinctly sinuate in posterior half in dorsal view; punctation moderately coarse, rather dense, and slightly irregularly distributed.

Elytra (Fig. 27) 0.94 times as long as pronotum; punctation moderately dense and moderately coarse, nearly regularly distributed; pubescence dense, not particularly long, and sub-depressed. Hind wings present. Metatarsomere I shorter than the combined length of II-IV.

Abdomen (Fig. 42) narrower than elytra, with moderately deep anterior impressions on tergites III-V; tergites III-V each with a transverse row of fine, sparse, and weakly defined puncture-like impressions in anterior impressions, with few lateral setiferous punctures on either side, and minute setiferous punctures at posterior margin, disc with scattered micropunctation; tergite VI with a broad transverse band of fine nonsetiferous punctures in anterior portion, with scattered micropunctation on disc, with few lateral setiferous punctures bearing long dark setae on either side and with numerous fine setiferous punctures near posterior margin; tergite VII with a broad band of fine non-setiferous punctation in anterior portion, with non-setiferous micropunctation and larger punctures on remainder of disc, with some lateral setiferous punctures bearing long dark setae on either side, and with fine setiferous punctures near posterior margin, posterior margin with palisade fringe; tergite VIII with numerous setiferous punctures in posterior half, posterior margin convex.

${ }^{*}$ : sternite VIII with strongly convex posterior margin; median lobe of aedeagus $0.83 \mathrm{~mm}$ long and shaped as in Figs 73-74; paramere $0.75 \mathrm{~mm}$ (Fig. 75) long and with very short apical lobe.

o: unknown.
Comparative notes: Based on the very short apical lobe of the paramere, on the shapes of the ventral process and of the internal structures of the aedeagus, and on the punctation pattern of the abdomen, $Z$. flavorufus belongs to the $Z$. hirtus group. It is distinguished from most species of this group by the shorter and less dense pubescence of the forebody and of the abdomen. In habitus, coloration, and other external characters, $Z$. flavorufus is highly similar to Z. matangensis CAMERON, 1943 and Z. parahirtus Assing, 2017, both from Borneo. It is distinguished from these species by more distinctly sinuate lateral margins of the pronotum, somewhat more slender antennae with less transverse preapical antennomeres, longer elytra with more distinct punctation, finer and sparser non-setiferous punctation on tergites VI and VII, and by the shape of the median lobe of the aedeagus.

Distribution: This species has been recorded only from the type locality in Java.

\subsubsection{Southeastern continental Asia}

\section{Zyras (Zyras) geminus (KRAATZ, 1859)}

Material examined: Thailand: 1 ex., Yala prov., Betong, Gunung Cang Dun vill., III-IV.1993, leg. Horák (MZMB). Vietnam: 1 ex., Ninh Binh province, Cuc Phuong National Park, $20^{\circ} 15^{\prime} \mathrm{N}, 105^{\circ} 43^{\prime} \mathrm{E}, 200 \mathrm{~m}$, at light, 3-5.V.2014, leg. Bartolozzi et al. (MZUF); 1 ex., same data, but 5-6.IV.2017, leg. Bartolozzi (cAss).

Comment: Zyras geminus had already been recorded from Vietnam. For a map illustrating the distribution of this widespread and common species see Assing (2017).

\section{Zyras (Zyras) wei PACE, 1993 \\ (Figs 76-77)}

Material examined: Laos: $1 \sigma^{\star}, 3$ ㅇ + , Phongsali Province, Phongsali env., 1300-1500 m, 1-15.V.2004 (cMar, cAss). Vietnam: 1 \% , $10 \mathrm{~km} \mathrm{NW} \mathrm{Sa} \mathrm{Pa}, 22^{\circ} 22^{\prime} \mathrm{N}, 103^{\circ} 45^{\prime} \mathrm{E}$, $1850 \mathrm{~m}$, moist stream valley with deciduous trees, litter and roots between rocks sifted, 8.VIII.2013, leg. Wunderle (cWun).

Comment: Confirmed records of $Z$. wei were known from the Chinese provinces Guizhou, Zhejiang, Fujian, and Sichuan (Assing 2016a). The above specimens from Phongsali represent the first record from Laos. The specimen from Vietnam was reported as Zyras sp. 2 in Assing (2015). Since it is a female, this record should be considered tentative, also because the elytra are completely blackish. The aedeagus of the male from Laos is illustrated in Figs 76-77. 


\section{Zyras (Zyras) notaticornis PACE, 1998}

(Figs 78-80)

Material examined: Laos: $10^{\star}, 1+$, Phongsali Province, Phongsali env., 1300-1500 m, 1-15.V.2004 (cMar, cAss).

Comment: This species was known from Hong Kong and the Chinese provinces Guangxi and Zhejiang (Assing 2016a). The above specimens represent the first record from Laos. Unlike the previously examined specimens from China and Hong Kong, those from Laos have the elytra and abdomen practically completely black. The aedeagus of the male from Laos is illustrated in Figs 78-80.

\section{Zyras (Zyras) rutrilobatus spec. nov.

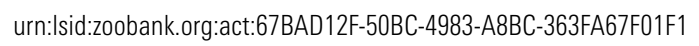 (Figs 9, 31, 45, 81-86)}

Type material examined: Holotype $\sigma^{*}:$ "N LAOS, 13001500 m, Phongsali Prov., Phongsali env., 2004, 1-15 May, Lao collector leg. / Holotypus ơ Zyras rutrilobatus sp. n., det. V. Assing 2017” (cMar).

Etymology: The specific epithet (derived from the Latin noun rutrum: shovel) is an adjective and alludes to the shovel-shaped ventral process of the aedeagus.

Description: Body length $6.0 \mathrm{~mm}$; length of forebody $2.8 \mathrm{~mm}$. Coloration (Figs 9, 31, 45): forebody black; abdomen black with the paratergites and the posterior margins of the posterior tergites paler brown; legs yellowish with the pro- and mesofemora, and the apical halves of the metafemora dark-brown; antennae blackishbrown with antennomeres I-II reddish-brown, X brown, and XI reddish-brown; maxillary palpi pale-brown with the apical palpomere yellowish-red.

Head (Fig. 31) distinctly transverse; punctation moderately coarse and very sparse; median dorsal portion extensively impunctate. Eyes large, much longer than postocular region in dorsal view. Antenna (Fig. 9) $2.3 \mathrm{~mm}$ long and slender; antennomeres IV-VII distinctly oblong, VIII weakly oblong, IX approximately as long as broad, X weakly transverse, and XI nearly as long as the combined length of IX and X.

Pronotum (Fig. 31) strongly transverse, 1.21 times as broad as long and 1.30 times as broad as head, broadest in anterior half; posterior angles obtusely marked; lateral margins not sinuate in posterior half in dorsal view; punctation moderately coarse and very irregularly distributed, laterally with extensive impunctate patches; pubescence long, pale, and sub-erect.

Elytra (Fig. 31) nearly 0.9 times as long as pronotum, distinctly dilated posteriad; punctation rather sparse and moderately coarse, somewhat sparser posteriorly than anteriorly; pubescence similar to that of pronotum. Hind wings present. Metatarsomere I as long as the combined length of II-IV.
Abdomen (Fig. 45) distinctly narrower than elytra, with deep anterior impressions on tergites III-V; tergites III-V each with a transverse row of moderately coarse and rather weakly defined puncture-like impressions in anterior impressions; tergite III with 1-2 lateral setiferous punctures on either side and with numerous setiferous punctures at or near posterior margin; tergites IV-V with a lateral setiferous puncture on either side, with a median pair of setiferous punctures, and with numerous setiferous punctures at posterior margins; tergite VI with a narrow transverse band of sparse non-setiferous punctures anteriorly, with few lateral setiferous punctures on either side, with a median pair of setiferous punctures in posterior portion, and with numerous setiferous punctures at posterior margin; tergite VII with a narrow transverse band of sparse non-setiferous punctures anteriorly and with two transverse rows of setiferous punctures posteriorly, posterior margin with palisade fringe; posterior margin of tergite VIII weakly concave in the middle (Fig. 84).

$\sigma^{7}$ : sternite VIII (Fig. 85) longer than tergite VIII, wegdeshaped, and with truncate posterior margin (Fig. 86); median lobe of aedeagus (Figs 81-82) nearly $0.9 \mathrm{~mm}$ long and with ventral process of distinctive shape; paramere (Fig. 83) $0.95 \mathrm{~mm}$ long and with very long, somewhat flattened apical lobe.

o: unknown.

Comparative notes: Based on the morphology of the median lobe of the aedeagus, the derived shape of the paramere (very long and flattened apical lobe), the modifications of the male sternite VIII, and external characters (long and slender antennae; body glossy with sparse punctation and long pubescence), Z. rutrilobatus is closely related to Z. glabricollis ScheErpeltz, 1965, Z. nitens Cameron, 1944, Z. truncatus Assing, 2017, and allied species. The geographically closest species of this group is Z. nitens (Peninsular Malaysia), from which $Z$. rutrilobatus differs by a much broader, larger, and more robust body, a much more transverse pronotum, darker coloration of the body, the femora, and the antennae, more massive antennae, more finely punctate elytra, a larger median lobe of the aedeagus with a ventral process of completely different shape, and by the longer apical lobe of the paramere. For illustrations of $Z$. nitens see Assing (2017).

Distribution and natural history: The type locality is situated near Phongsali in North Laos at an altitude of 1300-1500 m.

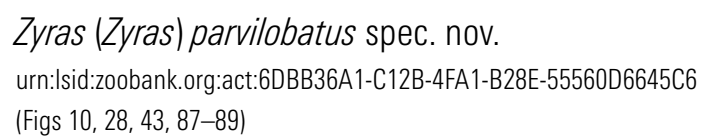

Type material examined: Holotype $\sigma^{7}$ : "N LAOS, 13001500 m, Phongsali Prov., Phongsali env., 2004, 1-15 May, 
Lao collector leg. / Holotypus ơ Zyras parvilobatus sp. n., det. V. Assing 2017” (cMar). Paratype: 1 \% : same data as holotype (cAss).

Etymology: The specific epithet is an adjective alluding to the relatively small ventral process of the aedeagus.

Description: Body length 5.8-6.5 mm; length of forebody 2.7-2.9 mm. Coloration (Figs 10, 28, 43): forebody blackish with the humeral and anterior portions of the elytra reddish-yellow; abdomen black with the posterior margins of the tergites more or less distinctly paler reddish; legs yellowish; antennae blackish with the apical portion of antennomere XI sometimes paler brown; maxillary palpi brown with the apical palpomere yellowish-red.

Head (Fig. 28) distinctly transverse; punctation moderately coarse and moderately sparse; along middle without punctation. Eyes large, much longer than postocular region in dorsal view. Antenna (Fig. 10) 1.9-2.1 mm long and moderately massive; antennomeres IV-V weakly oblong to weakly transverse, VI as long as broad or weakly transverse, VII-X weakly transverse, X less than 1.5 times as broad as long, and XI slightly longer than the combined length of IX and X.

Pronotum (Fig. 28) strongly transverse, 1.23-1.30 times as broad as long and 1.34-1.35 times as broad as head, broadest near anterior angles; posterior angles weakly, obtusely marked; lateral margins not sinuate in posterior half in dorsal view; punctation moderately coarse and moderately dense, regularly distributed; midline with or without narrow and somewhat irregular narrow impunctate band.

Elytra (Fig. 28) 0.82-0.85 times as long as pronotum; punctation rather dense and coarse, denser near scutellum than in posterior portion. Hind wings present. Metatarsomere I approximately as long as the combined length of II-IV.

Abdomen (Fig. 43) slightly narrower than elytra, with moderately deep anterior impressions on tergites III-V; tergites III-V each with a somewhat irregular transverse row or band of moderately coarse non-setiferous punctures in anterior impressions, with a lateral setiferous puncture on either side and with 4-6 setiferous punctures at posterior margins; tergite VI with a transverse band of rather sparse non-setiferous punctures anteriorly, with a transverse row of sparse setiferous punctures in posterior portion, and with six setiferous punctures at posterior margin; tergite VII with a transverse band of sparse non-setiferous punctures anteriorly and with two transverse rows of setiferous punctures posteriorly, posterior margin with palisade fringe; tergite VIII with setiferous punctures only in posterior fourth, posterior margin with sharply delimited concavity in the middle.

$\sigma^{\star}$ : sternite VIII with strongly convex posterior margin; median lobe of aedeagus (Figs 87-88) approximately $0.7 \mathrm{~mm}$ long; ventral process short in relation to capsule; paramere (Fig. 89) $0.8 \mathrm{~mm}$ long, apical lobe short and with four long dark setae.

: posterior margin of sternite VIII shallowly concave in the middle.

Comparative notes: Zyras parvilobatus is difficult to distinguish from the extremely similar, syntopic $Z$. wei based on external characters alone. The only reliable diagnostic characters are the distinctive shape of the median lobe of the aedeagus and the much shorter apical lobe of the paramere.

Distribution and natural history: The type locality is situated near Phongsali in North Laos at an altitude of $1300-1500 \mathrm{~m}$. Zyras rutrilobatus and Z. wei were found in the same locality.

Zyras (Zyras) hirtiventris spec. nov.

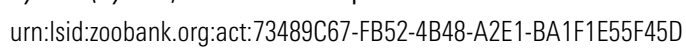

(Figs 11-12, 32, 49-50, 96-98)

Type material examined: Holotype $\sigma^{*}$ : "N LAOS, 1100$1300 \mathrm{~m}$, Phongsali Prov., Boun Tai (10 km SE), 2004, 16-25 May, Lao collector leg. / Holotypus o Zyras hirtiventris sp. n., det. V. Assing 2017" (cMar). Para-

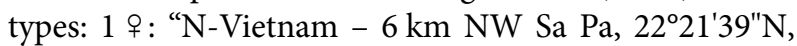
$103^{\circ} 47^{\prime} 19 " \mathrm{E}, 1810 \mathrm{~m}$, pasture margin, 7.VIII.2013, V. Assing [8+2]" (cAss); $10^{\star}$ : “C VIETNAM: Gia Lai Province, Kon Chu Rang Nature Reserve, surroundings HQ, about $900 \mathrm{~m}, 14^{\circ} 28,450^{\prime} \mathrm{N}, 108^{\circ} 32,401^{\prime} \mathrm{E} / \mathrm{leg}$. L. Bartolozzi, A. Bandinelli, S. Bambi, V. Sbordoni at light 8-12.V.2016 (nº Mag. 3078)" [registered as MZUF 18322; collected during expeditions in Vietnam in the framework of a Memorandum of Unterstanding between the Vietnam National Museum of Nature and MZUF] (MZUF).

Etymology: The specific epithet (with densely pubescent abdomen) is an adjective alluding to the dense setae on the abdominal sternites, as well as to the strong resemblance with $Z$. hirsutiventris (CHAMPION, 1927).

Description: Large species; body length $8.5-8.9 \mathrm{~mm}$; length of forebody $3.6-3.7 \mathrm{~mm}$. Coloration (Figs 11-12, 32, 49-50): body black with the posterior margin of the abdominal segment VII and all, or the posterior portion, of segment VIII dark reddish-brown; legs yellowish-brown with the profemora dark-brown and the meso- and metafemora bicoloured, basally yellowish and apically blackish-brown; antennae darkbrown to blackish with the apical antennomere reddish to reddish-brown; maxillary palpi brown with the apical palpomere yellowish.

Head (Fig. 32) distinctly transverse; punctation moderately coarse and rather dense, median dorsal portion extensively impunctate; pubescence long and sub-erect to erect, brown to black. Eyes moderately large, slightly longer than postocular region in dorsal view. Antenna 
(Figs 11-12) 2.4-2.5 mm long; antennomeres IV weakly oblong, V-VI weakly oblong to weakly transverse, VII-IX weakly to distinctly transverse, $\mathrm{X}$ approximately 1.5 times as broad as long, and XI short and of distinctly conical shape, much shorter than the combined length of IX and $\mathrm{X}$.

Pronotum (Fig. 32) 1.11-1.13 times as broad as long and 1.33-1.36 times as broad as head, broadest slightly anterior to middle, weakly convex in cross-section; posterior angles obtusely marked; lateral margins straight or very weakly sinuate in posterior half in dorsal view; punctation rather fine and dense, regularly distributed; midline without distinct impunctate band; pubescence long and sub-erect to erect, brown to black; lateral and anterior margins with longer and distinctly erect black setae.

Elytra (Fig. 32) 0.85-0.89 times as long as pronotum; punctation dense and moderately coarse, regularly distributed, and defined; pubescence dense, long, and brown to black. Hind wings fully developed. Metatarsomere I approximately as long as the combined length of II-IV.

Abdomen (Fig. 49) approximately as broad as elytra, with moderately deep anterior impressions on tergites III-V; tergites III-V each with a transverse row of fine to moderately coarse non-setiferous punctures in anterior impressions, with several lateral setiferous punctures on either side, with 6-10 setiferous punctures at posterior margins, and with moderately sparse to moderately dense non-setiferous micropunctation on discs; tergites VI-VII with extensive, dense, and coarse non-setiferous punctures anteriorly, with slightly sparser non-setiferous punctures on remainder of discs, and with some setiferous punctures laterally and at posterior margins (Fig. 50); posterior margin of tergite VII with palisade fringe; tergite VIII with dense and extensive non-setiferous punctation in posterior half and with dense and distinct setiferous punctation in posterior half, posterior margin convex, in the middle with very indistinct concavity; all sternites with long, dense, and sub-erect to erect pubescence in posterior portions (well visible from above).

$\sigma^{\star}$ : sternite VIII with convex posterior margin; median lobe of aedeagus approximately $0.9 \mathrm{~mm}$ long and shaped as in Figs 96-97; paramere (Fig. 98) $0.95 \mathrm{~mm}$ long, apical lobe short and with four long dark setae.

: posterior margin of sternite VIII shallowly concave in the middle.

Comparative notes: Based on the external and the male sexual characters, Z. hirtiventris undoubtedly belongs to the Z. hirtus group (see Assing 2017). In habitus, coloration, and other external and sexual characters, this species strongly resembles $Z$. hirsutiventris from the Himalayan region. It is distinguished from this species by larger body size (Z. hirsutiventris: body length $6.5-7.5 \mathrm{~mm}$; length of foreboedy $2.9-3.3 \mathrm{~mm}$ ), paler coloration of antennomere XI (black in Z. hirsutiventris), less fine and more defined punctation of the elytra, slightly darker coloration of the legs, denser and more extensive non-setiferous punctation of the posterior abdominal tergites, and a larger median lobe of the aedeagus with a ventral process of slightly different shape (Z. hirsutiventris: median lobe approximately $0.8 \mathrm{~mm}$ long; ventral process apically longer, more acute, and less distinctly angled in lateral view).

These differences may be clear-cut, though not pronounced, in the material examined thus far, but at present only three specimens of $Z$. hirsutiventris and three of $Z$. hirtiventris are known. The possibility that material with intermediate characters conditions will be found in the future and that the currently known material of $Z$. hirsutiventris and $Z$. hirtiventris only represents extreme forms of the same species cannot be ruled out with certainty. At present, the distributions of both taxa are separated by a distance of more than $1100 \mathrm{~km}$. This, in combination with the morphological differences observed, suggests that $Z$. hirsutiventris and Z. hirtiventris represent distinct species.

Distribution and natural history: The currently known distribution is confined to two localities in North Laos and North Vietnam. The altitudes range from approximately 1200 to $1810 \mathrm{~m}$. The female paratype was sifted from litter and roots beneath bushes and small trees at the margin of a pasture. It was recorded as Zyras (Zyras) sp. 1 by Assing (2015).

\section{Zyras (Zyras) hlavaci spec. nov.

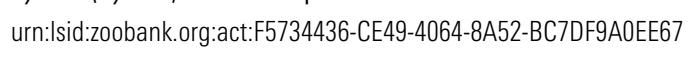 (Figs 13-14, 33, 48, 90-95)}

Type material examined: Holotype $\sigma^{*}$ : "MALAYSIA, Pahang state, Cameron Highlands, Tanah Rata, 14001650 m, 4.-11.4.2005, Martinů leg. / Holotypus o Zyras lunatus sp. n., det. V. Assing 2017” (cAss). Paratypes: 1 우 "MALAYSIA West, Pahang, Cameron Highlands, Tanah Rata, 1200-1500 m, 3.ii.-19.ii.2005, Cechovsky Petr leg." (cHla); $2 \sigma^{\star} \sigma^{*}$ : "MALAYSIA: Selangor, Ulu Gombak Field Studies Centre (250 m), 2-18.III.2004 (FIT), Maruyama M. et al." (cMar, cAss).

Etymology: This species is dedicated to my friend and colleague Peter Hlaváč (Prague), who provided, or arranged the loan of, substantial material not only for the present study, but also for previous revisions of Palaearctic and Oriental Zyras sensu strictu, and to whom I owe the generous gift of the holotype of this species.

Description: Body length 6.9-8.5 mm; length of forebody 3.0-3.5 mm. Coloration (Figs 13-14, 33, 48): forebody dark-brown to blackish; abdomen dark-reddish, with or without the antero-median portion of tergite VI diffusely infuscate and the antero-median portion of tergite VII indistinctly darker; legs yellowish to pale yellowish-brown; antennae brown to dark-brown; maxillary palpi reddishyellow to reddish with the apical palpomere yellowish. 
Head (Fig. 33) distinctly transverse; punctation moderately coarse to coarse and rather dense, median dorsal portion extensively impunctate; pubescence long, suberect to erect, and pale to brown. Eyes moderately large, as long as postocular region in dorsal view, or slightly longer. Antenna (Figs 13-14) 2.0-2.3 mm long; antennomeres IV approximately as long as broad or weakly oblong, $\mathrm{V}-\mathrm{X}$ of gradually increasing width and increasingly transverse, $\mathrm{X}$ approximately twice as broad as long, and XI of conical shape and short, shorter than the combined length of IX and X.

Pronotum (Fig. 33) 1.14-1.15 times as broad as long and 1.21-1.25 times as broad as head, broadest in anterior half, moderately convex in cross-section; posterior angles obtusely marked; lateral margins weakly sinuate in posterior half in dorsal view; punctation coarse, dense, and somewhat irregularly distributed, laterally and near posterior margin with impunctate patches; midline narrowly to broadly impunctate; pubescence long, pale, and suberect; lateral and anterior margins with numerous longer, stouter, and distinctly erect dark setae.

Elytra (Fig. 33) 0.85-0.89 times as long as pronotum; punctation moderately dense and moderately fine to moderately coarse, nearly regularly distributed, and defined; pubescence long, pale, and sub-erect. Hind wings fully developed. Metatarsomere I slightly shorter than the combined length of II-IV.

Abdomen (Fig. 48) nearly as broad as elytra, with moderately deep anterior impressions on tergites III-V; tergites III-V with non-setiferous punctation only in lateral portions of anterior impressions, with a transverse row of 4-8 setiferous punctures in posterior portions, with usually eight setiferous punctures at posterior margins, and with or without additional non-setiferous punctures on discs; tergite VI with dense and coarse non-setiferous punctation in anterior half, sparser nonsetiferous punctation in posterior half, with some lateral setiferous punctures, and with some setiferous punctures at posterior margin; tergite VII with dense non-setiferous punctation anteriorly, with sparser non-setiferous punctation on remainder of disc, and with two indistinct transverse rows of setiferous punctures posteriorly, posterior margin with palisade fringe; tergite VIII with setiferous punctures bearing a mix of yellowish and long black setae in posterior third and non-setiferous punctures in median third, posterior margin truncate or very weakly concave in the middle; all sternites with long and dense pubescence in posterior halves.

$\sigma^{\top}$ : sternite VIII with convex posterior margin; median lobe of aedeagus $0.83-0.90 \mathrm{~mm}$ long and shaped as in Figs 90-91, 93-94; ventral process slender and subapically distinctly angled; paramere (Figs 92, 95) approximately $0.9 \mathrm{~mm}$ long and with short apical lobe.

+ : posterior margin of sternite VIII weakly concave in the middle.

Intraspecific variation: The paratypes from Selangor are distinguished from the holotype by slightly smaller size, and by a slightly smaller aedeagus with an apically more acute ventral process (both in lateral and in ventral view) (Figs 90-91, 93-94). Since no additional evidence was found suggesting that the material from Pahang and from Selangor should represent distinct species, these differences are attributed to intraspecific variation.

Comparative notes: This species, too, belongs to the $Z$. hirtus group. It is distinguished from the similar $Z$. lunatus particularly by larger body size, darker coloration, by the punctation pattern of the abdomen (especially more extensive and denser non-setiferous punctation on the posterior tergites, also on tergite VIII), and by the more robust median lobe of the aedeagus with a more pronounced apex (ventral view). It differs from $Z$. flexus Assing, 2016 (China: Fujian) by somewhat larger body size, uniformly dark antennae (Z. flexus: antennomere XI yellowish), the presence of an impunctate median band on the less convex pronotum, less dense punctation of the elytra, denser and more extensive non-setiferous punctation on the abdomen, and by a distinctly larger median lobe of the aedeagus ( $Z$. flexus: $0.75 \mathrm{~mm}$ ).

Distribution and natural history: The type specimens were collected in three localities in Pahang and Selangor, Peninsular Malaysia, at altitudes between 250 and $1650 \mathrm{~m}$.

Zyras (Zyras) lunatus spec. nov.

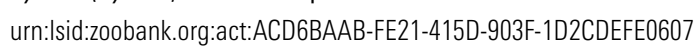
(Figs 15, 29, 47, 99-101)

Type material examined: Holotype $\sigma^{\star}$ : "MALAYSIA: Selangor, Ulu Gombak Field Studies Centre $(250 \mathrm{~m})$, 2-18.III.2004 (FIT), Maruyama M. et al. / Holotypus $0^{*}$ Zyras lunatus sp. n., det. V. Assing 2017” (cMar). Paratypes: $10^{\star}$ [teneral], 1 ㅇ: same data as holotype (cMar, cAss).

Etymology: The specific epithet is the past participle of the Latin verb lunare (to bend) and alludes to the subapically distinctly angled ventral process of the aedeagus.

Description: Body length 5.4-6.6 mm; length of forebody 2.6-2.9 mm. Coloration (Figs 15, 29, 47): head darkbrown to blackish; pronotum dark-brown; elytra brown to dark-brown with the suture paler; abdomen reddish with the posterior margins of tergites III-V, the posterior portions of tergites VI-VII, and all of tergite VIII yellowish-red; legs yellowish; antennae brown with antennomeres I-II reddish; maxillary palpi reddish with the apical palpomere yellowish.

Head (Fig. 29) distinctly transverse; punctation moderately coarse and moderately dense, median dorsal portion extensively impunctate; pubescence long, sub-erect to erect, and brown. Eyes moderately large, slightly longer than the postocular region in dorsal view. Antenna (Fig. 15) 2.0-2.1 mm long; antennomeres IV 
approximately as long as broad or weakly oblong, $\mathrm{V}$ as long as broad or weakly transverse, VI-X of gradually increasing width and increasingly transverse, $\mathrm{X}$ approximately 1.5 times as broad as long, and XI of conical shape and short, shorter than the combined length of IX and $\mathrm{X}$.

Pronotum (Fig. 29) 1.11-1.12 times as broad as long and 1.23-1.25 times as broad as head, broadest in anterior half, weakly convex in cross-section; posterior angles obtusely marked; lateral margins weakly to distinctly sinuate in posterior half in dorsal view; punctation rather coarse, dense, and somewhat irregularly distributed, laterally and near posterior margin with impunctate patches; midline rather broadly impunctate; pubescence long, pale, and sub-erect; lateral and anterior margins with numerous longer, stouter, and distinctly erect dark setae.

Elytra (Fig. 29) 0.81-0.87 times as long as pronotum; punctation moderately dense and moderately coarse, regularly distributed, and defined; pubescence dense, long, pale, and sub-erect. Hind wings fully developed. Metatarsomere I shorter than the combined length of II-IV.

Abdomen (Fig. 47) nearly as broad as elytra, with rather shallow anterior impressions on tergites III-V; tergites III-V without non-setiferous punctation in anterior impressions (individual punctures may be present), with a transverse row of approximately four setiferous punctures in posterior portions, and with usually eight setiferous punctures at posterior margins; tergite VI with a transverse band of fine non-setiferous punctation anteriorly, with sparse and fine non-setiferous punctures in median third, with some setiferous punctures laterally and with 8-10 setiferous punctures at posterior margin; tergite VII with a transverse band of dense non-setiferous punctures anteriorly, with sparse non-setiferous punctures in median third, and with two transverse rows of setiferous punctures posteriorly (each composed of approximately four punctures), posterior margin with palisade fringe; tergite VIII with setiferous punctures bearing long black setae in posterior third, posterior margin weakly concave in the middle; all sternites with long, dense, and erect yellowish pubescence (rubbed off in the holotype).

$\mathrm{o}^{\mathrm{t}}$ : sternite VIII with convex posterior margin; median lobe of aedeagus $0.68-0.75 \mathrm{~mm}$ long and shaped as in Figs 99-100; ventral process slender and subapically distinctly angled; paramere (Fig. 101) 0.78-0.84 mm long and with short apical lobe.

o : posterior margin of sternite VIII weakly concave in the middle.
Comparative notes: Like the syntopic Z. hlavaci, $Z$. lunatus belongs to the Z. hirtus group. It is distinguished from $Z$. hlavaci by smaller body size, more slender antennae, finer and less extensive non-setiferous punctation on the abdomen, and by a smaller aedeagus with a subapically more strongly angled, apically shorter, and in ventral view broader and apically less acute ventral process. It differs from the even smaller Z. formosanus Assing, 2016 (Taiwan) by a darker forebody, darker antennae with shorter antennomeres IV and V, much longer elytra, the punctation pattern of the abdomen (Z. formosanus: tergites III-VI with a transverse row of numerous long black setae posteriorly; tergites VI and VII with very sparse non-setiferous punctation anteriorly), and by a smaller aedeagus (despite larger body size) with a longer, subapically distinctly angled, and apically much more slender ventral process.

Distribution and natural history: The type locality is situated in Selangor, Peninsular Malaysia. The specimens were collected with flight interception traps, together with $Z$. hlavaci. One of the paratypes is slightly teneral.

\subsection{Species excluded from the Zyras sensu strictu}

Myrmedonota modiglianii (CAMERON, 1925), comb. nov. (Figs 18, 51-52, 102)

Myrmedonia (s. str.) modiglianii CAMERoN, 1925: $47 \mathrm{f}$.

Type material examined: Paratype $q:$ "Sumatra, Padang, 1890. E. Modigliani / Myrmedonia modigliani [sic] Cam Cotype / Syntype / Museo Civ. Genova / M. Cameron. Bequest., B.M. 1955-147. / Paratypus Myrmedonia modiglianii Cameron, rev. V. Assing 2017 / Myrmedonota modiglianii (Cameron), det. V. Assing 2017" (BMNH).

Comment: The original description is based on a male holotype from "Sumatra, Siboga" and an unspecified number of paratypes from "Padang" (CAMERON 1925). An examination of a female paratype revealed that this species does not belong to Zyras sensu strictu. According to Maruyama (e-mail 27. February, 2017), it belongs to Myrmedonota CAMERon, 1920. The external and female sexual characters are illustrated in Figs 18, $51-52,102$. 
4 Revised and updated catalogue of the species of Zyras sensu strictu of the Palaearctic and Oriental regions

A15 = Assing (2015); A16a = Assing (2016a); A16b = Assing (2016b); A17 = Assing (2017); App = Assing (present paper); B14 = Bernhauer (1914); B15 = Bernhauer (1915); B33a = Bernhauer (1933a); B33b = Bernhauer (1933b); B39 = Bernhauer (1939); C25 = CAMEron (1925); C30 = Cameron (1930); C39a = CAMERoN (1939a); C39b = CAMERoN (1939b); C43 = CAMERoN (1943); C44 = CAMERON (1944); Ch21 = CHAMPION (1921); Ch27 = CHAMPION (1927); D81 = DVoŘÁK (1981); D84 = DVoŘÁK (1984); D96 = DVOŘÁK (1996); F04 = FAUVEL (1904); HNM11 = HLAVÁČ et al. (2011); K59 = KRAATZ (1859); L69 = LAST (1969); L82 = LAST (1982); M61 = Motschulsky (1861); P86a = PACe (1986a); P86b = PACE (1986b); P86c = Pace (1986c); P87a = PACE (1987a); P87b = PACE (1987b); P88 = PACE (1988); P90 = PACE (1990); P92 = PACE (1992); P93 = PACE (1993); P98 = Pace (1998); P99 = Pace (1999); P01 = Pace (2001); P03 = Pace (2003); P04 = Pace (2004); P05 = PaCe (2005); P06 = Pace (2006); P08 = PACe (2008); P10 = PaCe (2010); P11 = Pace (2011); P12a = Pace (2012a); P12b = PaCE (2012b); P13 = PACE (2013); P14 = PACE (2014); S65 = SCheerPeltz (1965); St08 = SChubert (1908).

References are not given for the species distributed in the West Palaearctic region and Japan. Articles containing useful descriptions and illustrations, as well as new taxonomic acts and/or distribution maps are underlined.

\begin{tabular}{|c|c|c|}
\hline Species & Distribution & References \\
\hline abacus DvoŘÁK, 1984 & Kazakhstan, Kyrgyzstan & D84 \\
\hline $\begin{array}{l}\text { alternans (CAMERON, 1925) } \\
=\text { optimus CAMERON, } 1939\end{array}$ & $\begin{array}{l}\text { India; Malaysia: Malay Peninsula; Indonesia: } \\
\text { Java, Sumatra, Borneo }\end{array}$ & $\begin{array}{l}\text { A16a, }, \underline{A 17}, \mathrm{C} 25, \\
\text { C39a, P10 }\end{array}$ \\
\hline ambulans Assing, 2017 & Thailand & $\underline{\mathrm{A} 17}$ \\
\hline athetoides Assing, 2016 & China: Sichuan & $\underline{\mathrm{A} 16 \mathrm{a}}$ \\
\hline atronitens Assing, 2016 & China: Tibet & $\underline{\mathrm{A} 16 \mathrm{a}}$ \\
\hline bangmaicus Assing, 2016 & China: Yunnan & $\underline{\mathrm{A} 16 \mathrm{a}}$ \\
\hline $\begin{array}{l}\text { beijingensis PACE, } 1993 \\
=\text { restitutus PACE, } 1993\end{array}$ & China: Beijing, Gansu, Shaanxi, Zhejiang & A16a, P93 \\
\hline $\begin{array}{l}\text { bettotanus CAMERON, } 1930 \\
=\text { drescheri CAMERON, } 1939 \\
=\text { atrapicalis AssING, } 2016\end{array}$ & $\begin{array}{l}\text { China: Yunnan; Thailand; Peninsular Malaysia; } \\
\text { Indonesia: Java; Borneo (Malaysia, Indonesia, } \\
\text { Brunei) }\end{array}$ & $\frac{\mathrm{A} 16 \mathrm{a}}{\mathrm{C} 39 \mathrm{~b}}, \frac{\mathrm{A} 17}{\mathrm{P} 08}, \mathrm{C} 30$ \\
\hline bicoloricollis Assing, 2016 & China: Yunnan & A16a \\
\hline $\begin{array}{l}\text { birmanus SCHEERPELTZ, } 1965 \\
=\text { pseudobirmanus SCHEERPELTZ, } 1965\end{array}$ & Myanmar; China: Yunnan & $\underline{\mathrm{A} 16 \mathrm{a}}, \mathrm{A} 17, \mathrm{~S} 65$ \\
\hline bisinuatus Assing, 2016 & China: Yunnan & $\underline{\mathrm{A} 16 \mathrm{a}}$ \\
\hline brevilobatus Assing, 2017 & Thailand & $\underline{\mathrm{A} 17}$ \\
\hline $\begin{array}{l}\text { brignolii (PACE, 1986) } \\
=\text { thainiger PACE, } 2012\end{array}$ & Thailand; China: Yunnan & $\begin{array}{l}\text { A16a, A17, P86b, } \\
\text { P12b }\end{array}$ \\
\hline $\begin{array}{l}\text { bryanti CAMERON, } 1943 \\
=\text { mortuorum PACE, 1990, syn. nov. } \\
=\text { paederinus } \text { PACE, 2008, syn. nov. }\end{array}$ & $\begin{array}{l}\text { Thailand; Malaysia: Kelantan, Sarawak (Borneo), } \\
\text { Sabah (Borneo); Philippines }\end{array}$ & App, C43, P90, P08 \\
\hline caloderoides Assing, 2016 & China: Yunnan; Thailand & $\underline{\mathrm{A} 16 \mathrm{a}}, \mathrm{A} 16 \mathrm{~b}$ \\
\hline $\begin{array}{l}\text { castaneus (MOTSCHULSKY, 1861) } \\
=\text { adulescens } \text { (PACE, 1987) } \\
=\text { britannorum PACE, 1992 } \\
=\text { fratrumkadooriorum PACE, } 1998 \\
=\text { chumphonensis PACE, } 2004 \\
=\text { dibrugarhensis PACE, } 2011\end{array}$ & $\begin{array}{l}\text { Nepal; India; Sri Lanka; Thailand; Laos; China: } \\
\text { Yunnan; Hong Kong; Malaysia: Pahang, Sabah } \\
\text { (Borneo); Brunei; Indonesia: Java, Borneo }\end{array}$ & $\begin{array}{l}\text { A16a, A16b, } \underline{A 17}, \\
\text { App, M61, P87b, } \\
\text { P92, P98, P04, P08, } \\
\text { P11 }\end{array}$ \\
\hline championi CAMERoN, 1939 & North India: Uttar Pradesh & $\underline{\mathrm{A} 17}, \mathrm{C} 39 \mathrm{a}$ \\
\hline collaris (PAYKULL, 1789) & southern West Palaearctic & \\
\hline
\end{tabular}




\begin{tabular}{|c|c|c|}
\hline Species & Distribution & References \\
\hline $\begin{array}{l}\text { condignus LAST, } 1969 \\
=\text { distinctus } \text { CAMERON, } 1939\end{array}$ & North India: Uttarakhand; Nepal & $\begin{array}{l}\text { A16a, A17, C39a, } \\
\text { L69, P06, P13 }\end{array}$ \\
\hline cylindricornis DvoŘÁK, 1981 & Japan; Korea & D81 \\
\hline dabanicus Assing, 2016 & China: Qinghai & $\underline{\mathrm{A} 16 \mathrm{a}}$ \\
\hline densihirtus Assing, 2017 & Indonesia: Sulawesi Utara & $\underline{\mathrm{A} 17}$ \\
\hline densissimus Assing, 2017 & Indonesia: Sulawesi Utara & $\underline{\mathrm{A} 17}$ \\
\hline discolor Assing, 2016 & China: Fujian & $\underline{\mathrm{A} 16 \mathrm{a}}$ \\
\hline elegantulus CAMERON, 1939 & Indonesia: Java & App, C39b \\
\hline exspoliatus Assing, 2016 & China: Guangxi & A16a \\
\hline exasperatus SCHUBERT, 1908 & North India: Himachal Pradesh & $\underline{\mathrm{A} 17}, \mathrm{St} 08$ \\
\hline extensus Assing, 2016 & China: Yunnan & $\underline{\mathrm{A} 16 \mathrm{a}}$ \\
\hline $\begin{array}{l}\text { facundus LAST, } 1969 \\
=\text { semirufus CAMERON, } 1939\end{array}$ & Indonesia: Java & App, C39b, L69 \\
\hline fansipanicus Assing, 2015 & Vietnam & $\underline{\mathrm{A} 15}$ \\
\hline firmicornis Assing, 2016 & China: Fujian & $\underline{\mathrm{A} 16 \mathrm{a}}$ \\
\hline flavorufus CAMERon, 1939 & Indonesia: Java & App, C39b \\
\hline flexus Assing, 2016 & China: Fujian & $\underline{\mathrm{A} 16 \mathrm{a}}$ \\
\hline formosanus Assing, 2016 & Taiwan & A16a \\
\hline fugax (SHARP, 1888) & Japan, Korea & \\
\hline fulgidus (GraVEnHorst, 1806) & southern West Palaearctic & \\
\hline funestus (DvořÁк, 1996) & Vietnam & $\underline{\mathrm{A} 15}, \mathrm{D} 96$ \\
\hline gardneri CAMERON, 1939 & Nepal; North India & $\underline{\mathrm{A} 17}, \mathrm{C} 39 \mathrm{a}$ \\
\hline $\begin{array}{l}\text { geminus (KRAATZ, 1859) } \\
=\text { indicus CAMERON, } 1944 \\
=\text { shiva PACE, } 1987 \\
=\text { manjushri PACE, } 1992 \\
=\text { hongkongensis PACE, } 1999 \\
=\text { benenensis PACE, } 2001 \\
=\text { parageminus PACE, } 2010 \\
=\text { neoparageminus HLAVÁČ et al., } 2011 \\
=\text { subgeminus PACE, } 2012 \\
=\text { articollis Assing, } 2016\end{array}$ & $\begin{array}{l}\text { India; Nepal; Sri Lanka; China: Guangxi, } \\
\text { Yunnan; Taiwan; Hong Kong; South Japan; } \\
\text { Thailand; Laos; Vietnam; Indonesia }\end{array}$ & $\begin{array}{l}\text { A15, A16a, A16b, } \\
\text { A17, App, C44, } \\
\text { HNM11, K59, } \\
\text { P87b, P92, P99, } \\
\text { P01, P05, P06, P10, } \\
\text { P12b }\end{array}$ \\
\hline gilvipalpis Assing, 2016 & China: Yunnan & $\underline{\mathrm{A} 16 \mathrm{a}}$ \\
\hline glabricollis SCHEERPELTZ, 1965 & Myanmar & A16a, S65 \\
\hline granapicalis Assing, 2016 & China: Sichuan & $\underline{\mathrm{A} 16 \mathrm{a}}$ \\
\hline $\begin{array}{l}\text { granulipennis CAMERON, } 1930 \\
=\text { pervariolosus PACE, 2008, syn. nov. }\end{array}$ & Malaysia: Sabah (Borneo) & App, C30, P08 \\
\hline gratellus CAMERON, 1939 & Malaysia; Indonesia: Java, Sulawesi & $\underline{\mathrm{A} 17}, \mathrm{App}, \mathrm{C} 39 \mathrm{~b}$ \\
\hline hastatus FAUVEL, 1904 & South India & $\underline{\mathrm{A} 17}, \mathrm{~F} 04$ \\
\hline hauserianus BERNHAUER, 1933 & China: Heilongjiang, Xinjiang?; Kazakhstan? & A16a, A17, B33a \\
\hline $\begin{array}{l}\text { haworthi (STEPHENS, 1832) } \\
=\text { elegans }(\text { HEER, 1839) } \\
=\text { nigricollis MOTSCHULSKY, } 1845\end{array}$ & southern West Palaearctic & \\
\hline hebes Assing, 2016 & Taiwan & $\underline{\mathrm{A} 16 \mathrm{a}}$ \\
\hline hirsutiventris (СНAMPION, 1927) & Nepal; North India & $\underline{\mathrm{A} 17}, \mathrm{Ch} 27$ \\
\hline
\end{tabular}




\begin{tabular}{|c|c|c|}
\hline Species & Distribution & References \\
\hline hirtiventris spec. nov. & Laos; Vietnam & App \\
\hline hirtus (KRAATZ, 1859) & Sri Lanka; South India & $\underline{\mathrm{A} 16 \mathrm{a}}, \underline{\mathrm{A} 17}, \mathrm{~K} 59$ \\
\hline hlavaci spec. nov. & Malaysia: Pahang, Selangor & App \\
\hline illecebrosus LAST, 1982 & Mongolia & $\underline{\mathrm{A} 16 \mathrm{a}}, \underline{\mathrm{A} 16 \mathrm{~b}}, \mathrm{~L} 82$ \\
\hline inexcisus Assing, 2016 & $\begin{array}{l}\text { China: Gansu, Qinghai; Russia: Far East, East } \\
\text { Siberia }\end{array}$ & A16a \\
\hline iniquus Assing, 2016 & Pakistan; Afghanistan & $\underline{\mathrm{A} 16 \mathrm{a}}$ \\
\hline iridescens (SAWADA, 1970) & Japan & \\
\hline $\begin{array}{l}\text { kambaitiensis SCHEERPELTZ, } 1965 \\
=\text { ferrugineiventris SCHEERPELTZ, } 1965 \\
=\text { semiasperatus SCHEERPELTZ, } 1965\end{array}$ & Myanmar; China: Yunnan & A16a, S65 \\
\hline kinabaluensis PACE, 2008 & Malaysia: Sabah (Borneo) & $\underline{\text { App }}, \underline{\mathrm{P} 08}$ \\
\hline $\begin{array}{l}\text { kraatzi SCHUBERT, } 1908 \\
=\text { ignicauda }(\text { CHAMPION, 1927) }\end{array}$ & North India; Nepal & $\begin{array}{l}\text { A16a, A17, C39a, } \\
\text { Ch27, P87a, St08 }\end{array}$ \\
\hline latibasalis spec. nov. & Indonesia: Java; Laos? & App \\
\hline latilobatus Assing, 2017 & South India & $\underline{\mathrm{A} 17}$ \\
\hline lativentris Assing, 2016 & China: Yunnan & $\underline{\mathrm{A} 16 \mathrm{a}}$ \\
\hline longilobatus AssING, 2017 & North India: Meghalaya & $\underline{\mathrm{A} 17}$ \\
\hline lunatus spec. nov. & Malaysia: Selangor & App \\
\hline luteipes Assing, 2017 & India: Meghalaya & $\underline{\mathrm{A} 17}$ \\
\hline maculicollis Assing, 2016 & China: Hubei, Jiangxi, Sichuan & A16a, A16b \\
\hline maculipennis GRIDELLI, 1921 & Caucasus region; Middle Asia & \\
\hline malaisei SCHEERPELTZ, 1965 & Myanmar; Vietnam & $\mathrm{A} 15, \underline{\mathrm{A} 16 \mathrm{a}}, \mathrm{S} 65$ \\
\hline $\begin{array}{l}\text { matangensis CAMERON, } 1943 \\
=\text { daiaccorum PACE, 2008, syn. nov. }\end{array}$ & Malaysia: Sarawak, Sabah (Borneo) & $\frac{\mathrm{A} 17}{\mathrm{P} 03}, \underline{\mathrm{App}}, \mathrm{C} 08$ \\
\hline $\begin{array}{l}\text { montanus (BERNHAUER, 1915) } \\
=\text { variolatus PACE, 2003, syn. nov. }\end{array}$ & $\begin{array}{l}\text { Malaysia: Pahang, Kelantan, Sarawak (Borneo), } \\
\text { Sabah (Borneo); Indonesia: Kalimantan Tengah } \\
\text { (Borneo); Brunei }\end{array}$ & $\begin{array}{l}\underline{\mathrm{A} 17}, \underline{\mathrm{App}}, \mathrm{B} 15 \\
\underline{\mathrm{P} 03}, \underline{\mathrm{P} 08}, \underline{\mathrm{P} 14}\end{array}$ \\
\hline morulus Assing, 2017 & Nepal: Dhaulagiri, Annapurna & $\underline{\mathrm{A} 17}$ \\
\hline morvani PACE, 1986 & Nepal & P86c, $\underline{\mathrm{A} 17}$ \\
\hline $\begin{array}{l}\text { nigerrimus CAMERON, } 1943 \\
=\text { bartolozzii PACE, 2003, syn. nov. } \\
=\text { alboterminalis PACE, 2008, syn. nov. }\end{array}$ & $\begin{array}{l}\text { Malaysia: Pahang, Sabah, Sarawak (Borneo); } \\
\text { Indonesia: Kalimantan Tengah (Borneo) }\end{array}$ & $\begin{array}{l}\mathrm{A} 17, \underline{\mathrm{App}}, \mathrm{C} 43 \\
\mathrm{P} 08, \underline{\mathrm{P} 03}, \underline{\mathrm{P} 08}\end{array}$ \\
\hline nigrapicalis Assing, 2016 & $\begin{array}{l}\text { Myanmar; China: Yunnan, Sichuan; Taiwan; } \\
\text { Hong Kong }\end{array}$ & A16a, A17 \\
\hline nigricornis Assing, 2016 & China: Hubei, Gansu, Shaanxi, Sichuan, Qinghai & $\underline{\mathrm{A} 16 \mathrm{a}}$ \\
\hline nigrihirtus Assing, 2017 & Indonesia: Sulawesi Utara & $\underline{\mathrm{A} 17}$ \\
\hline nigroaeneus CAMERON, 1939 & North India & $\underline{\mathrm{A} 17}, \mathrm{C} 39 \mathrm{a}$ \\
\hline nigronitens Assing, 2016 & China: Yunnan & $\underline{\mathrm{A} 16 \mathrm{a}}$ \\
\hline nilgiriensis CAMERON, 1939 & South India & $\underline{\mathrm{A} 17}, \mathrm{C} 39 \mathrm{a}$ \\
\hline nitens CAMERON, 1944 & Malaysia: Selangor & $\underline{\mathrm{A} 17}, \mathrm{C} 44$ \\
\hline notaticornis PACE, 1998 & China: Guangxi, Zhejiang; Hong Kong; Laos & A16a, App, P98 \\
\hline $\begin{array}{l}\text { novinversus AssING, } 2017 \\
=\text { inversus } \text { PACE, 2012; preocc. }\end{array}$ & Thailand; Laos & $\underline{\mathrm{A} 17}, \mathrm{P} 12 \mathrm{~b}$ \\
\hline
\end{tabular}




\begin{tabular}{|c|c|c|}
\hline Species & Distribution & References \\
\hline optatus (SHARP, 1888) & Japan & \\
\hline pallipes PACE, 1992 & Nepal & A17, P92 \\
\hline pallipyga PACE, 2008 & Malaysia: Sabah (Borneo) & $\underline{\text { App }}, \underline{\mathrm{P} 08}$ \\
\hline $\begin{array}{l}\text { parageminus PACE, } 1998 \\
=\text { nameriensis } \mathrm{PACE}_{\mathrm{AC}} 2011\end{array}$ & India: Assam; Sri Lanka & $\underline{\mathrm{A} 17}, \mathrm{P} 88, \mathrm{P} 11$ \\
\hline parahirtus Assing, 2017 & Indonesia: Kalimantan Tengah (Borneo) & $\underline{\mathrm{A} 17}$ \\
\hline particornis (SHARP, 1888) & Japan; Korea; Russian Far East & \\
\hline parvicollis Assing, 2017 & Thailand & $\underline{\mathrm{A} 17}$ \\
\hline parvilobatus spec. nov. & Laos & App \\
\hline perforatus (СНАмріоN, 1921) & Nepal; North India & A16b, $\underline{\mathrm{A} 17}, \mathrm{Ch} 21$ \\
\hline pictus (SHARP, 1874) & Japan; Korea & \\
\hline $\begin{array}{l}\text { pindarae (CHAMPION, 1921) } \\
=\text { ruficauda CAMERoN, } 1939\end{array}$ & Nepal; India: Uttar Pradesh, West Bengal & $\begin{array}{l}\text { A16b, A17, C39a, } \\
\text { Ch21, P92, P06 }\end{array}$ \\
\hline porrectus Assing, 2016 & China: Sichuan & $\underline{\mathrm{A} 16 \mathrm{~b}}$ \\
\hline $\begin{array}{l}\text { preangeranus CAMERON, } 1939 \\
=\text { louwerensi CAMERON, } 1939 \\
=\text { chinkiangensis BERNHAUER, } 1939 \\
=\text { setosipennis } \text { SCHEERPELTZ, } 1965 \\
=\text { alboantennatus PACE, } 1986 \\
=\text { quadriterminalis PACE, } 2008 \text {, syn. nov. } \\
=\text { sichuanorum } \text { PACE, } 2012\end{array}$ & $\begin{array}{l}\text { Myanmar; China: Sichuan, Yunnan, Jiangsu; } \\
\text { Thailand; Laos; Vietnam; Malaysia: Selangor, } \\
\text { Pahang, Sabah, Sarawak (Borneo); Indonesia: } \\
\text { Java, Borneo }\end{array}$ & $\begin{array}{l}\text { A15, A16a, A17, } \\
\text { App, B39, P86a, } \\
\text { C39b, P08, P12a, } \\
\text { P12b, P14, S65 }\end{array}$ \\
\hline $\begin{array}{l}\text { proximus CAMERON, } 1939 \\
=\text { drugmandi } \mathrm{PACE}, 2004\end{array}$ & India; China: Guizhou; Thailand; Laos & $\underline{\mathrm{A} 17}, \mathrm{C} 39 \mathrm{a}, \mathrm{P} 04$ \\
\hline pulcher Assing, 2016 & China: Gansu, Sichuan & $\underline{\mathrm{A} 16 \mathrm{a}}$ \\
\hline punctipennis CAMERON, 1939 & Indonesia: Java, Borneo & App, C39b \\
\hline quasar DvoŘÁk, 1996 & Vietnam & $\underline{\mathrm{A} 15}, \underline{\mathrm{A} 16 \mathrm{~b}}, \mathrm{D} 96$ \\
\hline rectus Assing, 2016 & China: Yunnan & $\underline{\mathrm{A} 16 \mathrm{a}}$ \\
\hline rufapicalis Assing, 2016 & Taiwan & $\underline{\mathrm{A} 16 \mathrm{a}}$ \\
\hline rufoterminalis Assing, 2016 & China: Hubei, Sichuan & $\underline{\mathrm{A} 16 \mathrm{a}}$ \\
\hline russiceps Assing, 2017 & Thailand; Malaysia: Selangor & $\underline{\mathrm{A} 17}$ \\
\hline rutrilobatus spec. nov. & Laos & App \\
\hline schuelkei Assing, 2016 & China: Fujian, Sichuan, Guangxi & $\underline{\mathrm{A} 16 \mathrm{a}}, \mathrm{A} 16 \mathrm{~b}$ \\
\hline seminigerrimus BERNHAUER, 1933 & China: Sichuan & $\underline{\mathrm{A} 16 \mathrm{a}}$ \\
\hline setosivestis SCHEERPELTZ, 1965 & Myanmar & $\underline{\mathrm{A} 16 \mathrm{a}}, \mathrm{S} 65$ \\
\hline shaanxiensis PACE, 1998 & China: Gansu, Hubei, Shaanxi, Sichuan, Yunnan? & A16a, A16b, P98 \\
\hline sibiricus BERNHAUER, 1914 & Russian Far East; Japan; China: Beijing & $\underline{\mathrm{A} 16 \mathrm{a}}, \mathrm{B} 14$ \\
\hline song PACE, 1993 & China: Yunnan & A16a, P93 \\
\hline songanus PACE, 1993 & China: Beijing & $\underline{\mathrm{A} 16 \mathrm{a}}, \mathrm{P} 93$ \\
\hline subobsoletus Assing, 2016 & China: Sichuan & $\underline{\mathrm{A} 16 \mathrm{a}}$ \\
\hline tenebricosus Assing, 2016 & China: Sichuan, Tibet & $\underline{\mathrm{A} 16 \mathrm{a}}$ \\
\hline tenuicornis Assing, 2016 & Taiwan & $\underline{\mathrm{A} 16 \mathrm{a}}$ \\
\hline thaiorum PACE, 1986 & Thailand & A16a, P86a \\
\hline titan Assing, 2017 & Indonesia: Sulawesi Utara & $\underline{\mathrm{A} 17}$ \\
\hline
\end{tabular}




\begin{tabular}{|l|l|l|}
\hline Species & Distribution & References \\
\hline truncatus Assing, 2017 & Nepal: Dhaulagiri & $\underline{\mathrm{A} 17}$ \\
tumidicornis Assing, 2016 & China: Sichuan, Yunnan & $\underline{\mathrm{A} 16 \mathrm{a}}, \mathrm{A} 17$ \\
volans Assing, 2016 & Taiwan & $\underline{\mathrm{A} 16 \mathrm{a}}$ \\
wunderlei Assing, 2016 & Indonesia: Bali & $\underline{\mathrm{A} 16 \mathrm{~b}}$ \\
wei PACE, 1993 & $\begin{array}{l}\text { China: Fujian, Guizhou, Sichuan, Zhejiang; } \\
=\text { qingchengensis PACE, 2012 } \\
\text { yongshengensis PACE, 2012 }\end{array}$ & $\begin{array}{l}\text { Laos; Vietnam } \\
\text { China: Yunnan }\end{array}$ \\
\hline
\end{tabular}

\section{Acknowledgements}

My thanks are due to the colleages listed in the material section for the loan of material from the collections under their care, in particular to Peter Hlaváč (Prague) for the generous gift of the holotype of $Z$. hlavaci. Benedikt Feldmann (Münster) proof-read the manuscript.

\section{References}

Assing, V. 2015: On the Lomechusini fauna of Vietnam (Coleoptera: Staphylinidae: Staphylininae)._- Linzer Biologische Beiträge 47(2): 1257-1282 - http://www: zobodat.at/pdf/LBB_0047_2_1257-1282.pdff.

Assing, V. 2016a: A revision of Zyras STEPHENs sensu strictu of China, Taiwan, and Hong Kong, with records and (re-)descriptions of some species from other regions (Coleoptera: Staphylinidae: Aleocharinae: Lomechusini). - Stuttgarter Beiträge zur Naturkunde A, Neue Serie 9: 87-175.

Assing, V. 2016b: On some Lomechusini of the Palaearctic and Oriental regions (Coleoptera: Staphylinidae: Aleocharinae) ; _ Contributions to Entomology 66 (1): 13-111 - DOI:10.21248/contrib.entomol.66.1.13-111

Assing, V. 2017: Ō Zn Znas sensu strictu in the East Palaearctic and Oriental regions, with a focus on the faunas of the Himalaya, India, Sri Lanka, Thailand, and Sulawesi (Coleoptera: Staphylinidae: Aleocharinae: Lomechusini). - Contributions _ to Entomology 67(1):117-192 - DOI: $10.21248 /$ contrib.' entomol.67.1.117-192,

BERNHAUER, M. 1914: Neue Staphyliniden der paläarktischen Fauna. - Coleopterologische Rundschau 3(4): 65-68.

Bernhauer, M. 1915: Neue Staphyliniden der indomalaiischen Fauna, insbesondere der Sunda-Insel Borneo (9. Beitrag). - Verhandlungen der KaiserlichKöniglichen Zoologisch-Botanischen Gesellschaft in Wien 65: 134-158.

Bernhauer, M. 1933a: Neuheiten der chinesischen Staphylinidenfauna. - Wiener Entomologische Zeitung 50: 25-48.

Bernhauer, M. 1933b: Neues aus der Staphylinidenfauna China's. - Entomologisches Nachrichtenblatt 7(2): 39-54.
Bernhauer, M. 1939: Zur Staphylinidenfauna von China u. Japan. - Entomologisches Nachrichtenblatt 12(3-4): 145-158.

CAmeron, M. 1925: Descriptions of new species of oriental Staphylinidae. - Annali del Museo Civico di Storia Naturale di Genova 52: 34-49.

Cameron, M. 1930: Staphylinidae from British North Borneo, with descriptions of new species. - Journal of the Federated Malay States Museums 16: 160-168.

Cameron, M. 1939a: Coleoptera: Staphylinidae. Volume IV, Parts I-II. - Sewell, R. B. S. (ed): The Fauna of British India, including Ceylon and Burma., London: $691 \mathrm{pp}$.

Cameron, M. 1939b: Fauna Javanica. The Staphylinidae collected by Mr. F. C. Drescher. Part III. - Tijdschrift voor Entomologie 82: 1-29.

Cameron, M. 1943: New species of Staphylinidae (Col.) from Borneo. - Entomologist's Monthly Magazine 79: 39-42, 139-143, 183.

Cameron, M. 1944: Descriptions of new Staphylinidae (Coleoptera). - Proceedings of the Royal Entomological Society of London (B) 13: 11-15, 49-52, 104-108.

Champion, G. C. 1921: Some Indian Coleoptera (6). The Entomologist's Monthly Magazine 57: 177-184, 201-206.

Champion, G. C. 1927: Some Indian Coleoptera (23). The Entomologist's Monthly Magazine 63: 245-250.

Dvořák, M. 1981: Zwei neue ostasiatische Arten und nomenklatorische Bemerkungen zur Gattung Zyras (Coleoptera, Staphylinidae). - Acta Entomologica Bohemoslovaca 78: 53-60.

DvoŘÁK, M. 1984: Zur Kenntnis einiger myrmekophiler Staphylinidae (Coleoptera). - Acta Entomologica Bohemoslovaca 81: 190-203.

DvořÁk, M. 1996: Einige neue myrmekophile oder termitophile Arten des Tribus Zyrasini aus Südasien (Coleoptera, Staphylinidae, Aleocharinae). - Coleoptera Schwanfelder Coleopterologische Mitteilungen 23: 1-15.

Fauvel, A. 1904: Staphylinides de l'Hindoustan et de la Birmanie. - Revue d'Entomologie 23: 43-70.

HLaváč, P.; Newton, A. F. \& MaruYama, M. 2011: World catalogue of the species of the tribe Lomechusini (Staphylinidae: Aleocharinae). - Zootaxa 3075: 1-151. 
KraAtz, G. 1859: Die Staphylinen-Fauna von Ostindien, insbesondere der Insel Ceylan. - Archiv für Naturgeschichte 25(1): 1-193.

LAST, H. R. 1969: Changes in the nomenclature of the genus Zyras Stephens (Col., Staphylinidae). Entomologist's Monthly Magazine 104 [1968]: 279.

LAST, H. R. 1982: New species of Zyras from Mongolia (Coleoptera: Staphylinidae). - Acta Zoologica Academiae Scientiarum Hungaricae 28(1-2): 81-82.

Motschulsky, V. 1861: Essai d'un catalogue des insectes de l'ile Ceylan. 1-ière livraison. - Bulletin de la Société Impériale des Naturalistes de Moscou 34 (Première partie): 95-155.

PACE, R. 1986a: Aleocharinae della Thailandia e della Birmania riportate da G. de Rougemont (Coleoptera, Staphylinidae). - Bollettino del Museo Civico di Storia Naturale di Verona 11 [1984]: 427-468.

PACE, R. 1986b: Aleocharinae dell'Asia sudorientale raccolte dal Dr. Osella (Coleoptera, Staphylinidae). - Bollettino del Museo Civico di Storia Naturale di Verona 11 [1984]: 481-491.

PACE, R. 1986c: Aleocharinae dell'Himalaya raccolte da Guillaume de Rougemont (Coleoptera, Staphylinidae). - Bollettino del Museo Civico di Storia Naturale di Verona 12: 165-191.

PACE, R. 1987a: Staphylinidae dell'Himalaya nepalese. Aleocharinae raccolte dal Prof. Dr. J. Martens (Insecta: Coleoptera). - Courier des Forschungsinstitutes Senckenberg 93: 383-441.

PACE, R. 1987b: Aleocharinae dell'Asia sudorientale raccolte da G. de Rougemont (Coleoptera, Staphylinidae). - Bollettino del Museo Civico di Storia Naturale di Verona 13 [1986]: 139-237.

PACE, R. 1988: Aleocharinae dello Sri Lanka raccolte da Marc Tronquet (Coleoptera Staphylinidae). Bollettino del Museo Civico di Storia Naturale di Verona 14 [1987]: 315-338.

PACE, R. 1990: Aleocharinae delle Filippine. $82^{\circ}$ contributo alla conoscenza delle Aleocharinae. - Berti, N. (ed.): Miscellanées sur les Staphylins. Mémoires du Muséum National d'Histoire Naturelle (A, Zoologie) 147: 57-113.

PACE, R. 1992: Aleocharinae nepalesi del Museo di Ginevra. Parte VI: Myrmedoniini (Coleoptera, Staphylinidae). - Revue Suisse de Zoologie 99(1): 125-145.

PACE, R. 1993: Aleocharinae della China (Coleoptera, Staphylinidae). - Bollettino del Museo Civico di Storia Naturale di Verona 17 [1990]: 69-126.

PACE, R. 1998: Aleocharinae della Cina: Parte IV (Coleoptera, Staphylinidae). - Revue Suisse de Zoologie 105(4): 911-982.

Pace, R. 1999: Aleocharinae di Hong Kong (Coleoptera, Staphylinidae). - Revue Suisse de Zoologie 106(3): 663-689.

PACE, R. 2001: Aleocharinae aus Vietnam in der Sammlung des Naturkundemuseums Erfurt (Coleoptera, Staphylinidae). - Veröffentlichungen Naturkundemuseum Erfurt 20: 193-200.
PAce, R. 2003: Aleocharinae della Penisola di Malacca (Malaysia) (Coleoptera, Staphylinidae). - Bollettino del Museo Regionale di Scienze Naturali, Torino 20(1): 33-78.

PACE, R. 2004: Aleocharinae di Thailandia, Cambogia, Laos e Malaysia (Coleoptera, Staphylinidae). Belgian Journal of Entomology 6: 243-302.

PACE, R. 2005: Nuovo contributo alla conoscenza delle Aleocharinae dell'India (Coleoptera, Staphylinidae). Nouvelle Revue d'Entomologie (N.S.) 22(2): 141-153.

PACE, R. 2006: Aleocharinae del Nepal al Naturkundemuseum diErfurt (Insecta: Coleoptera: Staphylinidae). 343-408. - In: Hartmann, M. \& Weipert, J. (eds): Biodiversität und Naturausstattung im Himalaya. Volume II - Verein der Freunde und Förderer des Naturkundemuseums Erfurt e.V., Erfurt.

PACE, R. 2008: Generi e specie della tribù Lomechusini del Borneo (Coleoptera, Staphylinidae). - Revue Suisse de Zoologie 115(1): 107-156.

PACE, R. 2010: Aleocharinae della regione Orientale al Museo di Genova (Coleoptera, Staphylinidae). Annali del Museo Civico di Storia Naturale "G. Doria" 102: 295-335.

PACE, R. 2011: Aleocharinae from India gathered by Guillaume de Rougemont (Coleoptera, Staphylinidae). - Lavori della Società Veneziana di Scienze Naturali 36: $23-40$.

PACE, R. 2012a: Biodiversità delle Aleocharinae della Cina: Lomechusini e Thamiaraeini (Coleoptera, Staphylinidae). _- Beiträge zur Entomologie 62(1): 77-102 - DOI:110.21248/contrib.entomol.62.1.77-102

PACE, R. 2012b: New data, new species, and two new genera of Aleocharinae from the Oriental Region (Insecta: Coleoptera: Staphylinidae). - Vernate 31: 319-360.

PACE, R. 2013: Nuovo contributo alla conoscenza delle Aleocharinae del Nepal (Insecta: Coleoptera: Staphylinidae). - Vernate 32: 347-370.

PACE, R. 2014: Aleocharinae from Sabah (Borneo) collected by Guillaume de Rougemont (Coleoptera, Staphylinidae). - Linzer Biologische Beiträge 46(1): 727-794.

Scheerpeltz, O. 1965: Wissenschaftliche Ergebnisse der Schwedischen Expedition 1934 nach Indien und Burma. Coleoptera Staphylinidae (except. Megalopsidiinae et Steninae). - Arkiv för Zoologie 17(2): 93-371.

SchuberT, K. 1908: Beitrag zur Staphylinidenfauna Ostindiens (West-Himalaya). (Col.) - Deutsche Entomologische Zeitschrift 1908: 609-625.

Schülke, M. \& SMetana, A. 2015: Staphylinidae: 304-1134. - In: LöвL, I. \& LöвL, D. (eds): Catalogue of Palaearctic Coleoptera. Volume 2. Hydrophiloidea - Staphylinoidea., Revised and updated Edition Brill, Leiden - ISBN 9789004289925. 